\title{
A Novel Fault Line Selection Method Based on Improved Oscillator System of Power Distribution Network
}

\author{
Xiaowei Wang, Jie Gao, Xiangxiang Wei, and Yaxiao Hou \\ School of Electrical Engineering and Automation, Henan Polytechnic University, Jiaozuo 454000, China \\ Correspondence should be addressed to Xiaowei Wang; proceedings@126.com
}

Received 8 April 2014; Revised 8 June 2014; Accepted 28 June 2014; Published 21 July 2014

Academic Editor: Pak-Kin Wong

Copyright ( 2014 Xiaowei Wang et al. This is an open access article distributed under the Creative Commons Attribution License, which permits unrestricted use, distribution, and reproduction in any medium, provided the original work is properly cited.

\begin{abstract}
A novel method of fault line selection based on IOS is presented. Firstly, the IOS is established by using math model, which adopted TZSC signal to replace built-in signal of duffing chaotic oscillator by selecting appropriate parameters. Then, each line's TZSC decomposed by db10 wavelet packet to get CFB with the maximum energy principle, and CFB was solved by IOS. Finally, maximum chaotic distance and average chaotic distance on the phase trajectory are used to judge fault line. Simulation results show that the proposed method can accurately judge fault line and healthy line in strong noisy background. Besides, the nondetection zones of proposed method are elaborated.
\end{abstract}

\section{Introduction}

When SPG fault occurs in power distribution network, fault line selection method is always study emphasis. For the arc suppression coil grounding system, the fault current is very weak, and judging the fault line accurately becomes more difficult. Therefore, power distribution network in china is also called small current to ground system. For a long time, many scholars did a lot of studies about fault line selection and came up with many novel methods of different theories, which obtained some achievements [1-7].

The signal processing tools, such as wavelet transform (WT), S-transform, Prony method, and Hough Transform, which used to obtain fault signals feature in many methods. Then, many papers establish fault line selection criterion with artificial neural network [8] or support vector machine [9]. In [1], the paper adopted WT to study SPG fault, it used good localization ability in time and frequency domain to extract the characteristic of transient signal on different scales, but WT is easily influenced by noise. Besides, different waveletbased functions have different results for characteristic of transient signal. In [2], TZSC data of first T/4 is used, and Stransform is carried out to determine the main characteristic frequency. Therefore, fault line selection result is detected by comparing S-transform energies of each feeder line. To avoid TAs density effect of magnetic saturation, paper [3] puts forward a piecewise Prony method; it improved the precision of the traditional Prony method, and the proposed method was used to match TZSC signals to get fault information. In [4], Hough transform was used to achieve fault line selection; actually, Hough transform has an excellent performance in the case of not exceeding two-dimensional parameter space, but if parameter space increased, calculation amount will rise sharply, meanwhile, costly storage space and timeconsumption also will be surged. Paper [8] presents a method based on rough membership neural network to classify 10 kinds of fault types about transmission line. In [9], support vector machine (SVM) has advantages of solving small sample size, nonlinear and high dimensional pattern recognition problems; however, its identifying ability is influenced by selfparameters easily.

Chaotic oscillator detection method has some advantages, such as it can effectively extract weak signals under the noise background, it is sensitive to small periodic signals, and it has certain immunity to noise. Therefore, the application areas of the method are very wide., for example, arcing faults protection [10], fault diagnosis of wind turbine gearbox [11], faults line detection [12], and islanding detection [13].

This paper proposed a novel method of fault line selection based on IOS. Firstly, in the aspect of extracting feature signal, 


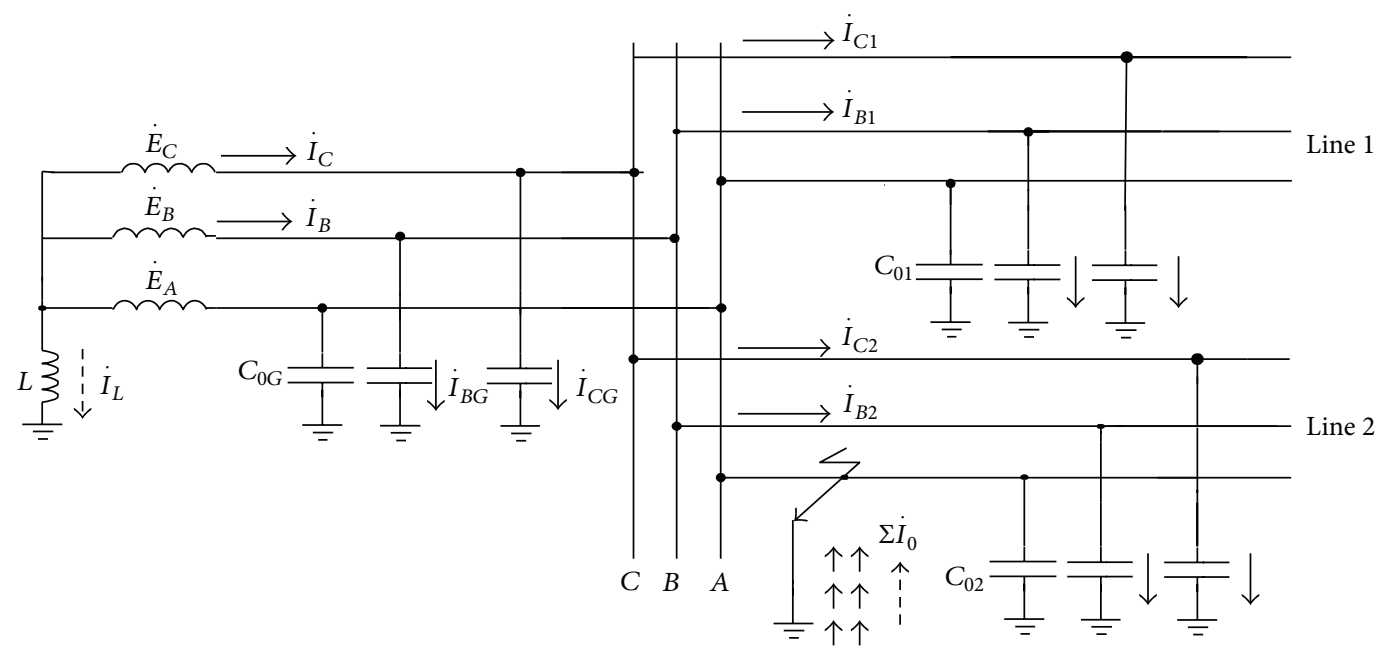

FIGURE 1: Current flow of SPG fault.

TZSC is decomposed by db10 wavelet packet. Next, according to the maximum energy principle, CFB is selected and is inputted to IOS. Finally, fault line selection criterion based on maximum chaotic distance and average chaotic distance of phase trajectory is presented to judge the fault line.

The remaining of this paper is arranged as follows. In Section 2, we analyzed the small current to ground fault. In Section 3, we indicated duffing chaotic oscillator disadvantage that cannot detect the damped oscillation signal. In Section 4, we introduced the IOS work principle. In Section 5, we proposed the fault line selection method and introduced the wavelet packet theory and detection factor setting. In Section 6, we simulated the small current to ground fault and verified the effectiveness of proposed method. In Section 7, the nondetection zone of proposed method is presented. A brief summary concludes the paper in Section 8.

\section{Analysis of Small Current to Ground Fault}

When SPG fault occurs in small current to ground system, the current flow distribution is shown in Figure 1.

In Figure 1, the power's neutral point attached an arc suppression coil, so current flow has a change by the coil, but capacitor voltage amplitude and distribution are both the same as nonsolidly grounded system. However, the difference is that inductive current $\dot{I}_{L}$ flow from line to ground point. Therefore, the total current is

$$
\dot{I}_{f}=\dot{I}_{L}+\dot{I}_{C \Sigma}
$$

where $\dot{I}_{C \Sigma}$ and $\dot{I}_{L}$ were capacitance current to ground and inductance current, respectively. Using $L$ to represent inductance, so $\dot{I}_{L}=-\dot{E}_{A} / j \omega L$.

Phase difference between $\dot{I}_{C \Sigma}$ and $\dot{I}_{L}$ is $180^{\circ}$, so $\dot{I}_{f}$ will decrease due to arc suppression coil compensation. When the coil runs with over compensation stage, the residual current to ground is inductive. Reactive power flow direction of

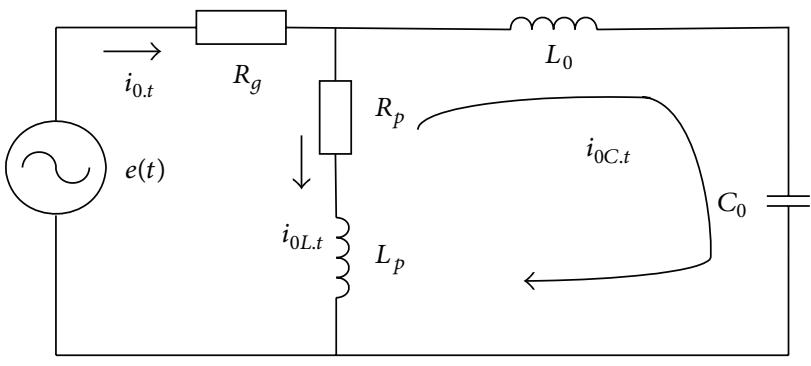

FIGURE 2: Transient zero-sequence equivalent circuit.

capacitive is from bus line to fault line, it is same as healthy line. Therefore, the fault information is less.

Transient zero-sequence equivalent circuit of SPG fault is used to analyze TZSC. In Figure 2, $C_{0}, L_{0}$ are zero-sequence capacitance and zero-sequence inductance, respectively; $R_{g}$ is transition resistance; $R_{p}, L_{p}$ are equivalent resistance and inductance of arc suppression coil respectively; $e(t)$ is zerosequence voltage.

In Figure 2, TZSC $i_{0 . t}$ is [14]

$$
\begin{aligned}
i_{0 . t}= & i_{0 L . t}+i_{0 C . t} \\
=I_{L m} \cos \varphi e^{-t / \tau_{L}}+I_{C m}( & \frac{\omega_{f}}{\omega} \sin \varphi \sin \omega t \\
& \left.\quad-\cos \varphi \cos \omega_{f} t\right) e^{-\delta t},
\end{aligned}
$$

where $i_{0 L . t}, i_{0 C . t}$ are inductive current and capacitive current of TZSC and their initial values are $I_{L m}$ and $I_{C m}$, respectively $\left(I_{\mathrm{Cm}}=U_{\mathrm{ph} m} \omega C, I_{L m}=U_{\mathrm{ph} m} / \omega L\right), U_{\mathrm{ph} m}$ is phase voltage amplitude, $\omega$ is angular frequency of power frequency, $\omega_{f}, \delta$ are oscillation angular frequency and attenuation coefficient of TZSC, $\tau_{L}$ is decay time constant of inductive current, and $\varphi$ is initial phase angel.

When SPG fault occurs, ground point will flow transient capacitive current and transient inductive current; the former has fast attenuation speed and the later has slow speed, and 


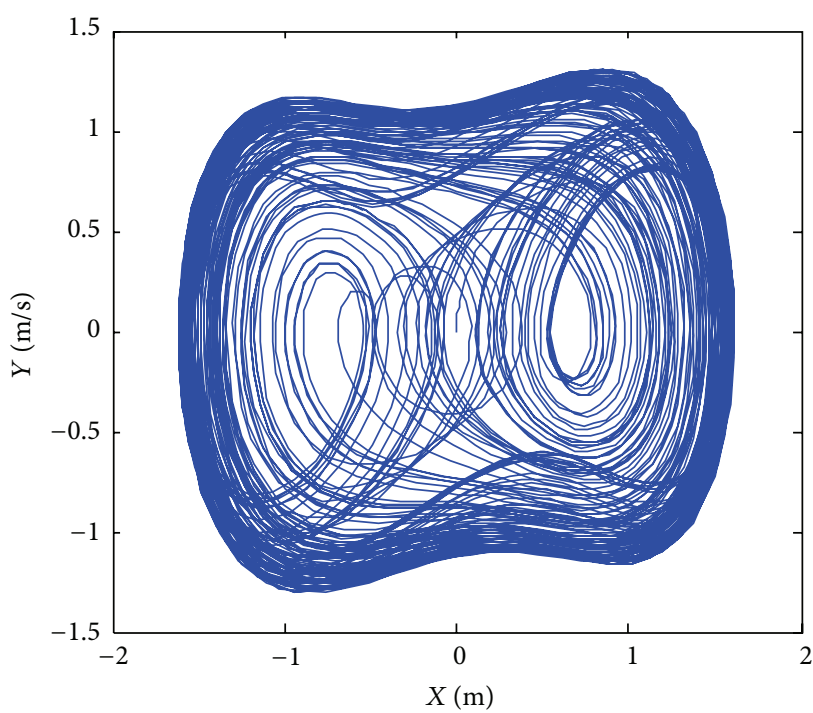

(a) Chaotic state

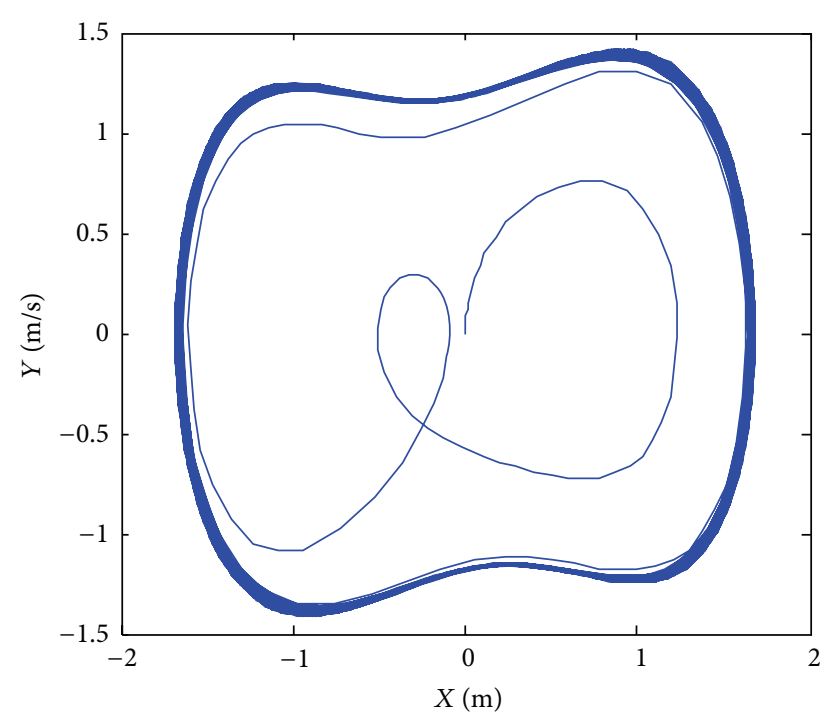

(b) Periodic state

FIGURE 3: Different states of phase trajectories.

$i_{0 \text { C.t }}$ determined the amplitude and frequency of $i_{0 . t}$. With power lines length increasing, the self-oscillation frequency decreases, and the free oscillation component amplitude of $i_{0 C . t}$ also decreases; meanwhile, free oscillation duration will be reduced to half power frequency cycle. Moreover, the distribution network is a small current to ground system, so fault signal is weak, and it influenced by noise easily. Therefore, TZSC difference between fault line and healthy line is small, and the fault information is less; it was difficult to achieve fault line selection for distribution networks.

In recent years, duffing chaotic oscillator detection method is used widely, because it is sensitive to small periodic signal and has immunity to noise. Therefore, it can be used to detect weak signals in strong noisy background for power distribution networks.

\section{Duffing Chaotic Oscillator Disadvantage}

The Holmes-type duffing chaotic oscillator has two characteristics.

(1) System motion state is not influenced by large amplitude of irregular noise.

(2) System motion state changed by the periodic signal, its frequency is the same as the system, even if the signal is very weak.

Holmes-type duffing equation is given as follows:

$$
x^{\prime \prime}+k x^{\prime}-x+x^{3}=\gamma f_{1}(t),
$$

where $x, k$, and $f_{1}(t)$ are output signal, damping ratio, and built-in signal, respectively, $\gamma$ is amplitude factor of built-in signal, and $f_{1}(t)$ is equal to $\cos (t)$ generally.

If $\gamma$ is equal to 0.8 and 0.82625 , respectively, we can get chaotic state and periodic state; it is shown in Figure 3.

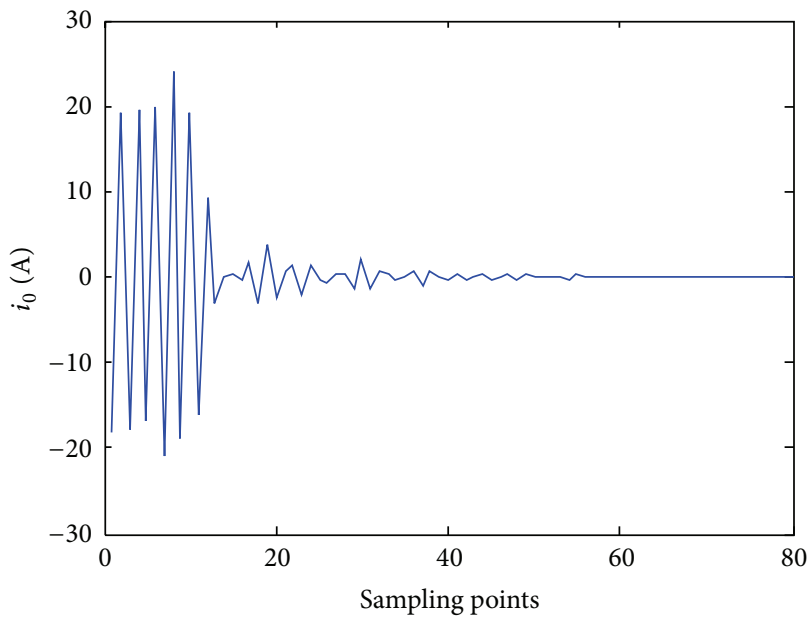

FIgURE 4: Damped oscillation signal.

In Figure 3, the system has different states by setting different $\gamma$ values. Therefore, duffing chaotic oscillator detecting method usually used system's different states to detect different signals.

Considering the external signal variability, (3) is changed by scale variation. Then, add measured signal, it is shown as follows:

$$
\ddot{x}+\omega k \dot{x}-\omega^{2} x^{3}+\omega^{2} x^{5}=\gamma \cos (\omega t)+f_{2}(t) .
$$

Here, $\omega$ is angular frequency of measured signal, $f_{2}(t)$ is external signal.

We choose damped oscillation signal to study, it contains a range of frequency components; it was shown in Figure 4; Figure 5 is obtained by calculating (4).

It showed that duffing oscillator detection system is not influenced by mutative amplitude of external signal in 


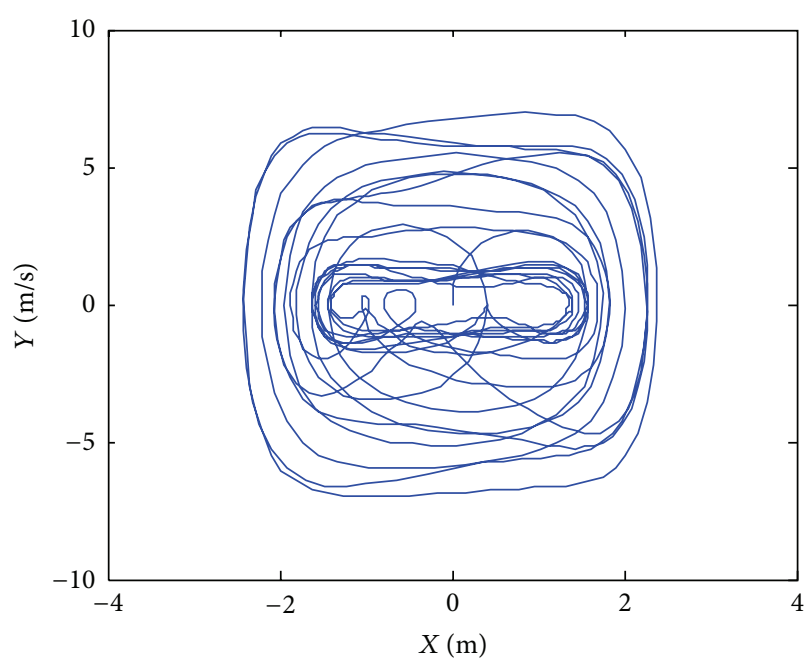

(a) Original amplitude

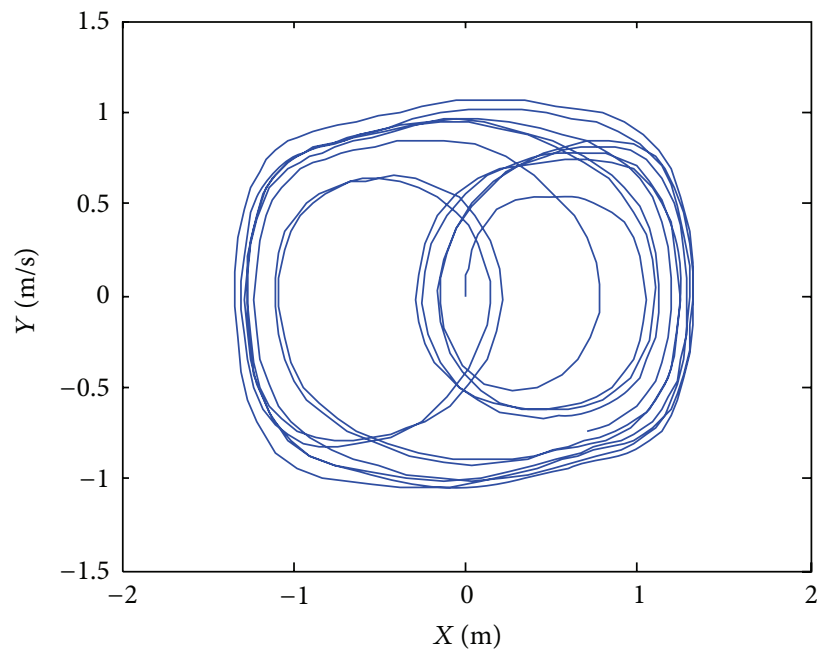

(c) Amplitude reduced 100 times

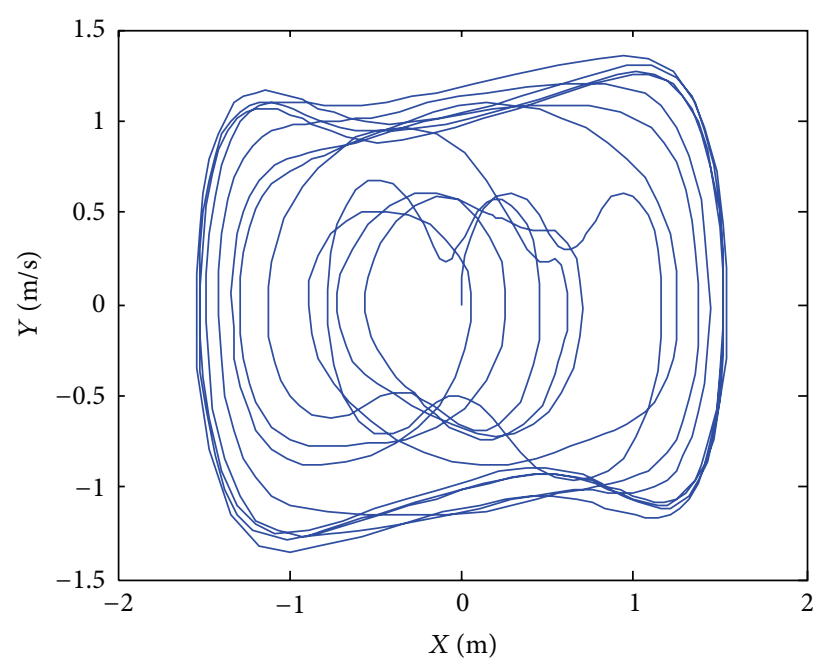

(b) Amplitude reduced 10 times

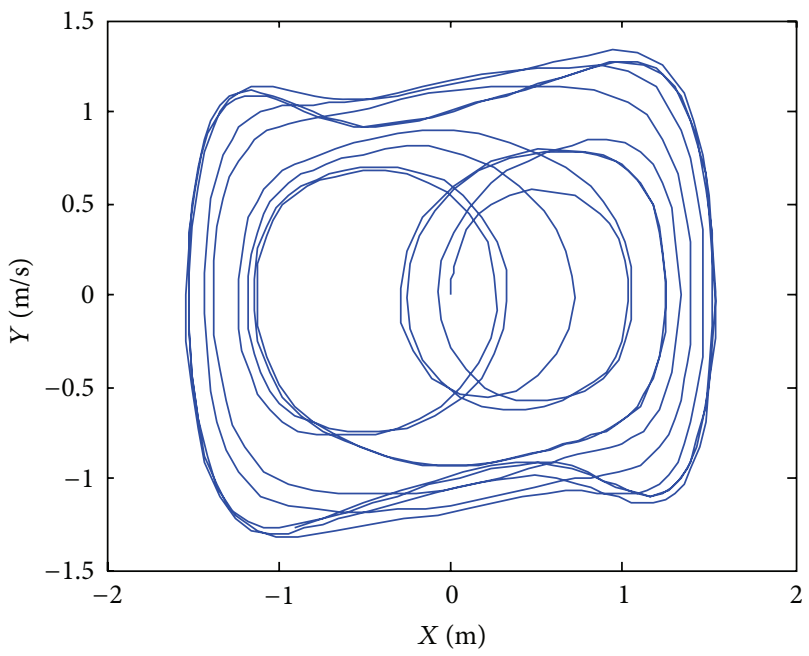

(d) Amplitude reduced 1000 times

Figure 5: Phase trajectories of different amplitudes.

Figure 5. The reason is that external signal has different frequencies, but the system has only one frequency. Therefore, the damped oscillation signal cannot make duffing chaotic oscillator turn to other states, in other words, the duffing oscillator detection system has weak detection ability for damped oscillation signal.

\section{IOS Work Principle}

TZSC signal of small current to ground system is shown in Figure 6.

In Figure 6, TZSC signal has oscillation and attenuation states, and (2) shows that different TZSC have different oscillation and attenuation states. Therefore, TZSC math model is proposed. Consider the following:

$$
\begin{aligned}
i(t)= & A_{1} \cos \left(2 \pi \omega_{0} t+\varphi_{1}\right)+A_{2} e^{\delta_{1} t} \cos \left(2 \pi \omega_{0} k_{1} t+\varphi_{2}\right) \\
& +A_{3} e^{\delta_{2} t} \cos \left(2 \pi \omega_{0} k_{2} t+\varphi_{3}\right)+A_{4} e^{\delta_{3} t} .
\end{aligned}
$$

Equation (5) consists of four components, where $A_{i}, k_{1}$, $k_{2}, \delta$ and $\varphi_{j}$ are component amplitude, natural number, decimal number, attenuation coefficient, and initial phase, respectively, $i=1,2,3,4$, and $j=1,2,3$. Each component, respectively, represents fundamental component, integer harmonic, noninteger harmonics, and attenuation component.

In order to make up for the disadvantage that cannot detect damped oscillation signal, the built-in signal $f_{1}(t)$ is replaced by (5); therefore, IOS is proposed and shown as follows:

$$
\begin{gathered}
x^{\prime}=y, \\
y^{\prime}=-k y+x^{3}-x^{5} \\
+\gamma\left(\cos \left(2 \pi \times \omega_{0} t\right)\right. \\
+e^{-t} \cos \left(2 \pi \times \omega_{0} \times 1 \times t\right)
\end{gathered}
$$




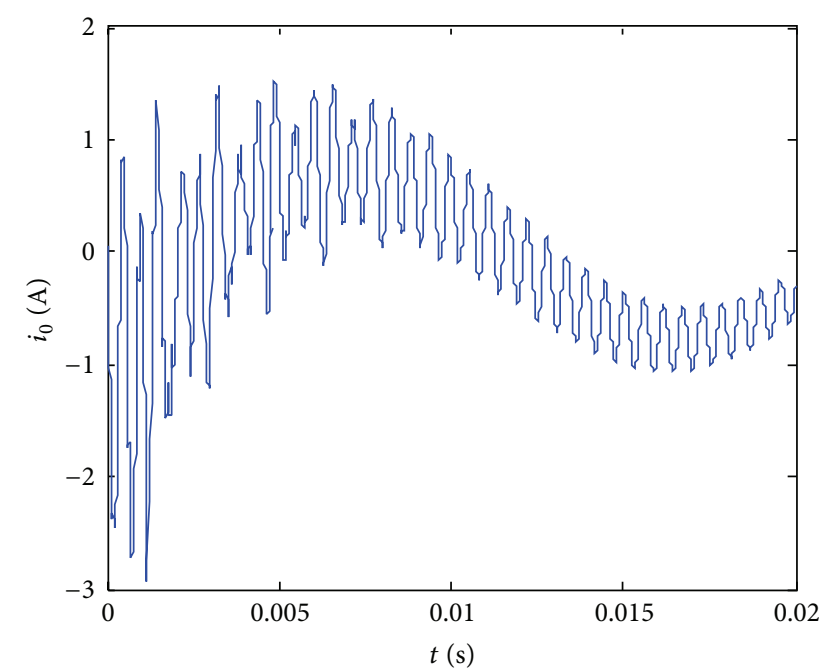

Figure 6: TZSC signal.

$$
\begin{aligned}
& \left.+e^{-t} \cos \left(2 \pi \times \omega_{0} \times 1.1 \times t\right)+e^{-t}\right) \\
& +\beta \times f_{2}(t),
\end{aligned}
$$

where $A_{i}=1(i=1,2,3,4), \omega_{0}=50, k_{1}=1, k_{2}=1.1$, $\delta=-1, \varphi_{j}=0, \gamma$ is amplitude factor of built-in signal, and $\beta$ is detection factor.

4.1. Amplitude Factor Impact. If $f_{2}(t)=0, k=0.5$, and $\gamma$ is equal to $10^{-4}, 0.025,0.03$, and 0.035 , respectively, the IOS phase trajectories are shown in Figure 7.

Comparing Figure 3 with Figure 7, in this paper, the state of Figure 7(a) is named chaotic-like state (CLS). Similarly, Figures $7(\mathrm{~b})$ and $7(\mathrm{c})$ are named critical state (CS), Figure $7(d)$ is named periodic-like state (PLS).

In Figure 7(a), when IOS is in CLS, points movement are small on phase trajectory, motion tendency is obscure, and it is integrally in chaotic state. When $\gamma$ increased to a certain value, the phase trajectory turned to PLS; its movement scale is big and movement tendency is clear; the overall movement state can be thought as circular movement with reduced radius; it is shown in Figure $7(\mathrm{~d})$.

CS is between CLS and PLS, and the overall movement state can be thought as a curve segment keeping away from the origin point; it shows in Figures $7(\mathrm{~b})$ and $7(\mathrm{c})$.

4.2. Damping Ratio Influence. We used the PLS parameters and set damping ratio $k$ as equal to $0.01,0.05,0.5$, and 1 , respectively. By solving IOS, the phase trajectories are shown in Figure 8.

According to Figure 8, with damping ratio $k$ increasing, movement scale of phase trajectory becomes smaller; overall movement state changed from circular movement with decreasing radius to a clear curve segment. However, when $k$ decreased, movement scale became larger and overall movement state is from a clear curve segment turn to a closed curve. In other words, when $k$ increased from small to large, PLS phase trajectory followed: sparse $\rightarrow$ dense $\rightarrow$ sparse.

All in all, rational $k$ can make PLS phase trajectory become dense and make the difference between CS and CLS be more obvious; the phenomenon is more beneficial to identifying PLS. But, lower and bigger $k$ would make PLS turn to other states. Therefore, choosing the rational damping ratio is very important.

4.3. IOS Example. To demonstrate IOS detection ability, transient zero-sequence signal from paper [15] is chosen and inputted to IOS $(k=0.05, \gamma=0.002, \beta=0.001)$. By changing amplitudes and frequencies of transient zero-sequence signal, Figure 9 is obtained.

Figure 9(a) results are obtained by the changed frequency signal that comes from paper [15], on the contrary, Figures 9(b) and 9(c) results are obtained by changing the signal amplitude. Similarly, Figure $9(\mathrm{~d})$ results are obtained by importing the signal directly without change.

According to Figure 9, the example signal in the paper can make IOS have different phase trajectories. Therefore, different oscillation damping signals can generate different phase trajectories; it shows that IOS has superior ability to detect oscillation damping signals.

\section{Fault Line Selection Method}

5.1. Wavelet Packet Transform Theory. Wavelet packet transform (WPT) is an improved method of wavelet transform (WT), and it has better time-frequency resolution, therefore, it can effectively extract fault feature of TZSC signal. WPT is described as follows.

Defining $U_{j}^{n}$ is the closure space of $u_{n}(t)$, so $U_{j}^{2 n}$ is closure space of $u_{2 n}(t)$, and $u_{n}(t)$ meet the following two-scale equation:

$$
\begin{gathered}
u_{2 n}(t)=\sqrt{2} \sum_{l \in Z} h(l) u_{n}(2 t-l), \\
u_{2 n+1}(t)=\sqrt{2} \sum_{l \in Z} g(l) u_{n}(2 t-l),
\end{gathered}
$$

where $g(l)=(-1)^{l} h(1-l), h(l)$ and $g(l)$ have orthogonal relationship; when $n=0$, (7) can be expressed. Consider the following:

$$
\begin{aligned}
& u_{0}(t)=\sqrt{2} \sum_{k \in Z} h(l) u_{0}(2 t-l), \\
& u_{1}(t)=\sqrt{2} \sum_{k \in Z} g(l) u_{0}(2 t-l) .
\end{aligned}
$$

When $n$ is equal to $Z_{+}$, it can generalize $U_{j+1}^{n}=U_{j}^{n} \oplus$ $U_{j}^{2 n+1}, j \in Z, n=Z_{+}$, orthogonal wavelet packet is determined by basis function: $u_{0}(t)=\varphi(t)$. Since $\varphi(t)$ is determined by $h_{l}$ uniquely, so $\left\{u_{n}(t)\right\}$ is called the orthogonal wavelet packet about sequence $\left\{h_{l}\right\}$. About wavelet packet decomposition, it is the band-pass or low-pass filter actually. The filter bandwidth is $\left[f_{s}(l-1) / 2^{j}, f_{s} l / 2^{j}\right]$, where $j$ is level 


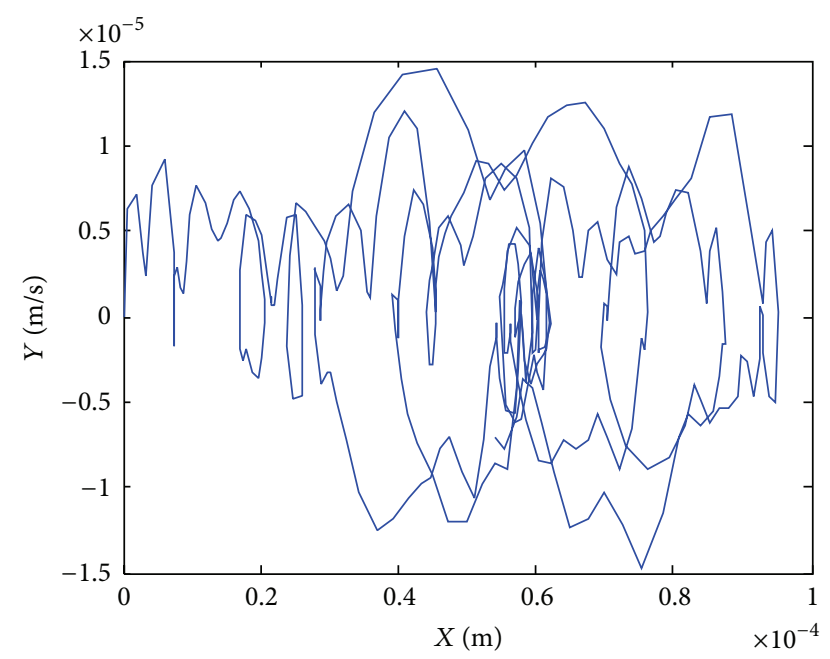

(a) $\gamma=10^{-4}$

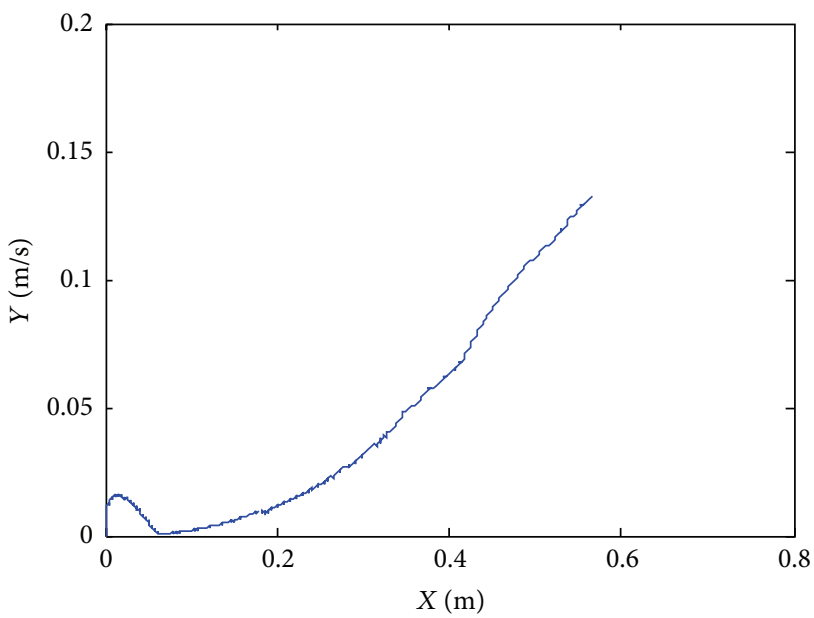

(c) $\gamma=0.03$

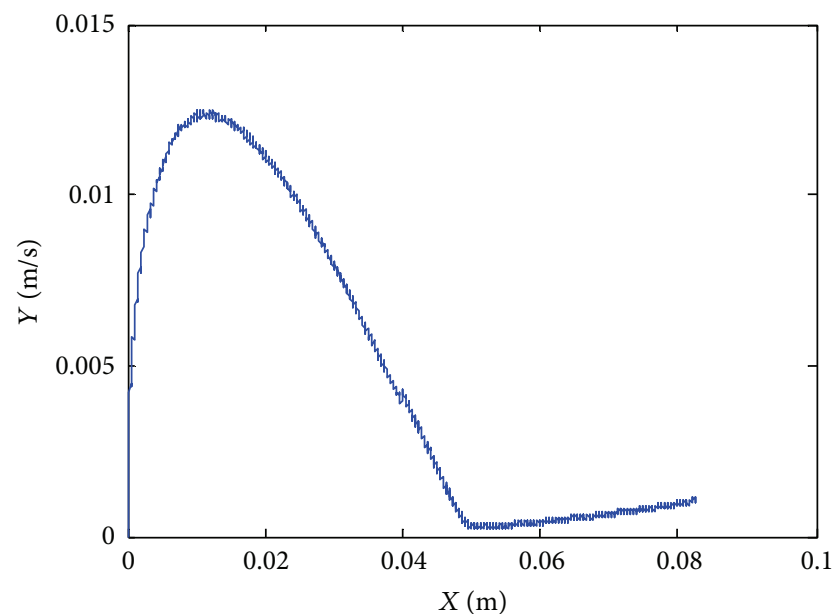

(b) $\gamma=0.025$

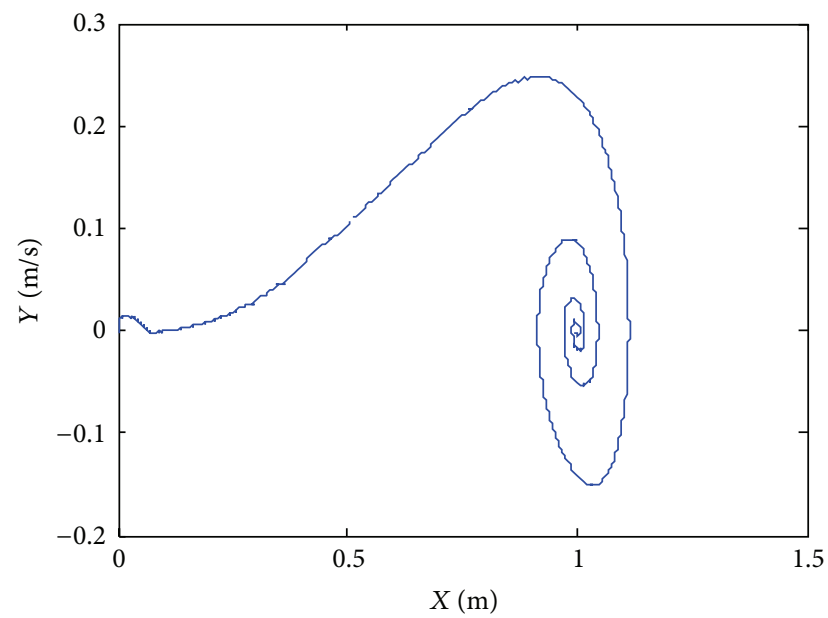

(d) $\gamma=0.035$

Figure 7: Phase trajectories of different $\gamma$.

number of wavelet decompositions, $l$ is the $l$ th contacts of wavelet decomposition, and $f_{s}$ is input signal frequency; WPT decomposition structure is shown in Figure 10.

$A$ is low-frequency, $D$ is high-frequency. The decomposition has the following equation.

$$
\begin{aligned}
S= & A A A_{3}+D A A_{3}+A D A_{3}+D D A_{3}+A A D_{3} \\
& +D A D_{3}+A D D_{3}+D D D_{3} .
\end{aligned}
$$

According to power signal feature, WPT can choose appropriate CFB to match signal spectrum adaptively; it improved time-frequency resolution and had a wide prospect. Because daubechies series wavelet has some merits, such as orthogonal characteristic, compact support, and $N-1$ vanishing moments; therefore, db10 wavelet packet is chosen to analyze TZSC signal.

5.2. Detection Factor Setting. Each line's TZSC is decomposed by $\mathrm{db} 10$ wavelet packet; then, the CFB is chosen by maximum energy principle, with the change of grounding resistance, the different CFB are obtained; it is shown in Figure 11.

In Figure 11, CFB is also damped oscillation signal, and its maximum amplitude decreased with fault resistance increasing. In other words, when fault situation changed, CFB amplitude will be changed. In order to make IOS have a better applicability, the detection factor $(\beta)$ should be chosen appropriately. Therefore, CFB was input to IOS, and the equation is proposed as follows:

$$
\begin{aligned}
& x^{\prime}=y, \\
& y^{\prime}=-k y+x^{3}-x^{5} \\
& +\gamma\left(\cos (2 \pi \times 50 t)+e^{-t} \cos (2 \pi \times 50 \times 1 \times t)\right. \\
& \left.\quad+e^{-t} \cos (2 \pi \times 50 \times 1.1 \times t)+e^{-t}\right) \\
& +\beta \times \xi_{k}^{(j)}(n),
\end{aligned}
$$




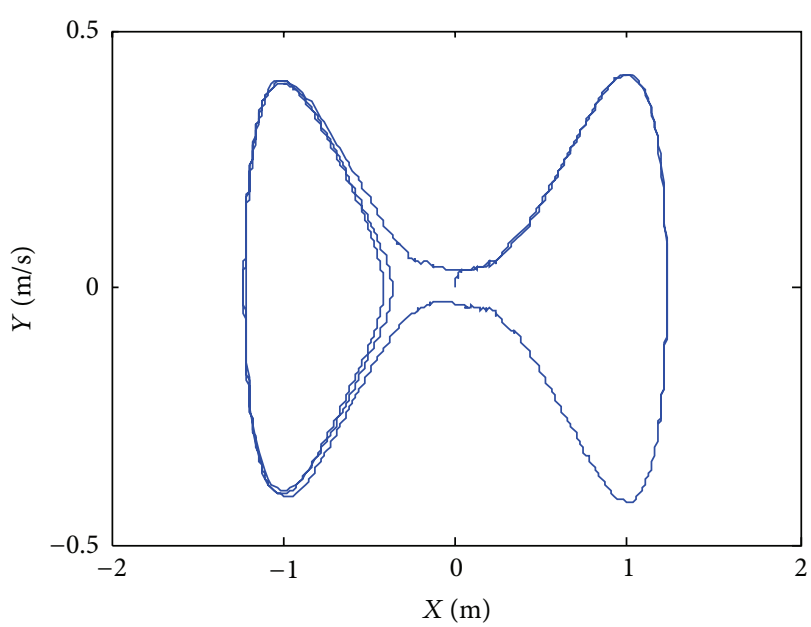

(a) $k=0.001$

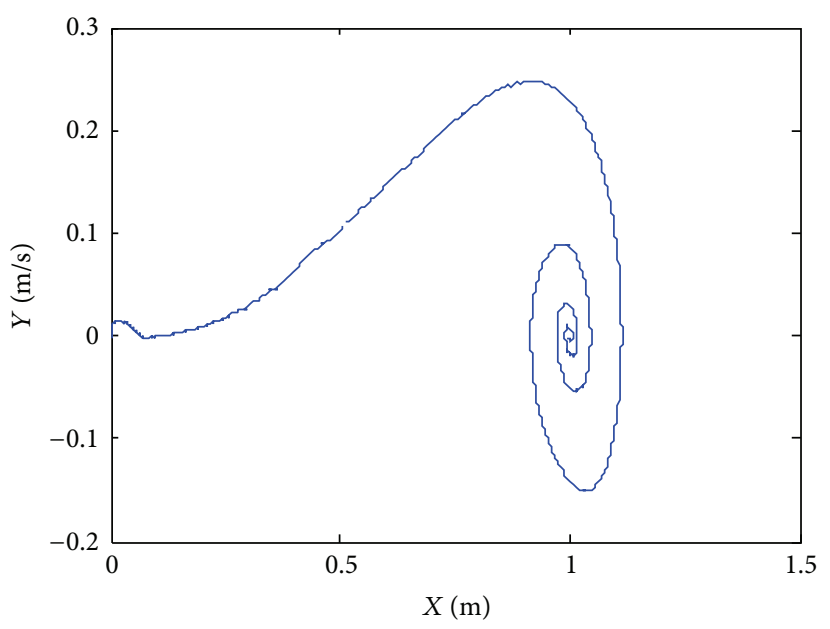

(c) $k=0.5$

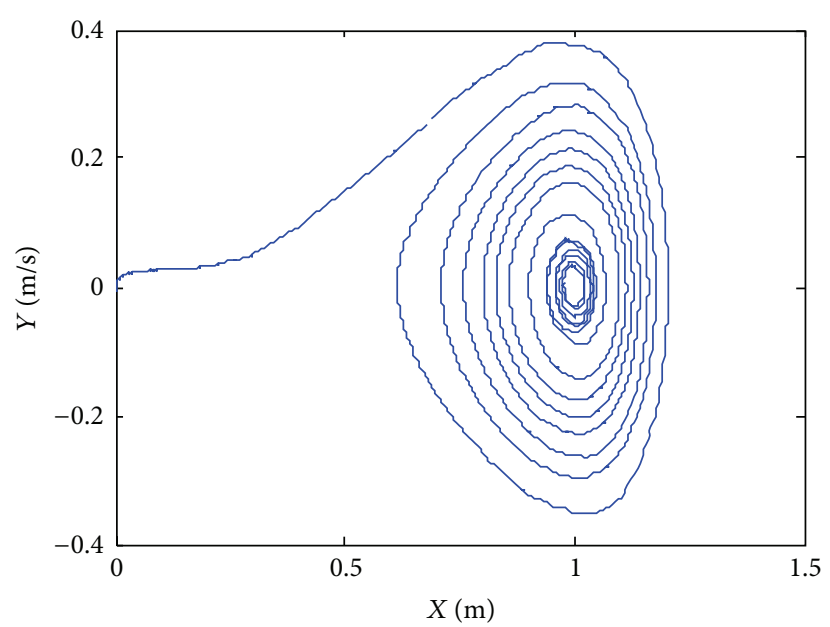

(b) $k=0.05$

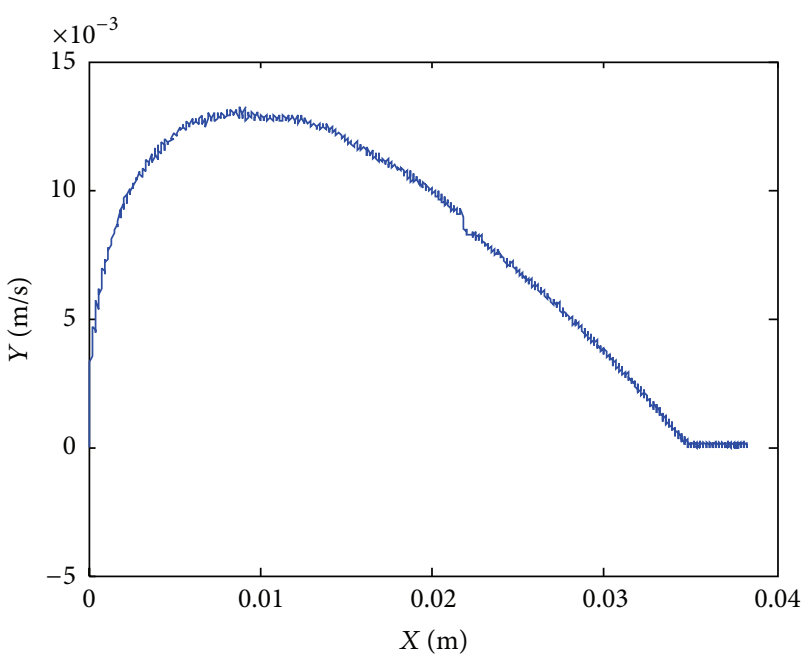

(d) $k=1$

Figure 8: Phase trajectories of different $k$.

where $\xi_{k}^{(j)}(n)$ is CFB signal, $k=0.05, \gamma=0.002$, and $\beta=0.000286$. The value of $\beta$ is chosen by a large number of experiments [12].

\subsection{Fault Line Selection Criterion Based on Chaos Distance.} Compared with paper [12], it is difficult to accurately distinguish between CS and PLS only by the phase trajectory; the reason is that their phase trajectories are very similar. Therefore, chaotic distance and average chaotic distance are put forward to distinguish the phase trajectory state.

Chaotic distance $\left(\mathbf{D}_{C}\right): \mathbf{D}_{C}$ is square distance from each point to origin point on phase trajectory; it can represent the size of each point movement scale:

$$
\mathbf{D}_{C}=(\mathbf{X}-0)^{2}+(\mathbf{Y}-0)^{2}
$$

$\mathbf{X}$ is the vector which is acquired by solving (4), $\mathbf{Y}$ is the firstorder differential vector of $\mathbf{X}$, and the maximum of $\mathbf{D}_{C}$ is named $M D_{C}$.
Average chaotic distance $\left(D_{A}\right): D_{A}$ is the average of $\mathbf{D}_{C}$; it can represent the overall movement scale:

$$
D_{A}=\frac{\sum \mathbf{D}_{C}}{m}
$$

$m$ is the number of points on phase trajectory.

By using the chaos distance, a range of CFB signals is chosen and inputted into IOS, by solving IOS, we get Figure 12.

In Figures 12(a) and 12(b), CLS scale is very small, and its points always move near the origin point, so the $\mathbf{D}_{C}$ of CLS is also very small. The $\mathbf{D}_{C}$ of CS increases with time increasing, which complies with curvilinear movement that is away from origin point; it is shown in Figures 12(c) and $12(\mathrm{~d})$. But $\mathbf{D}_{C}$ of PLS shows oscillation damping state, which complies circular movement with reducing radius; it is shown in Figures 12(e) and 12(f). Chaotic distance can clearly indicate movement scale and tendency of each state; it avoids error distinction. $M D_{C}$ and $D_{A}$ values of Figure 12 are shown in Table 1. 


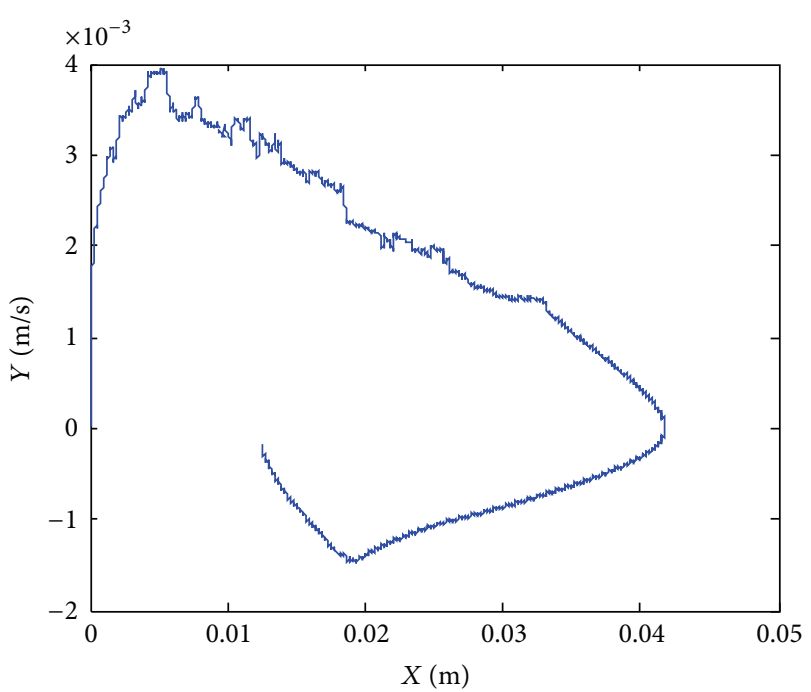

(a) Change frequency

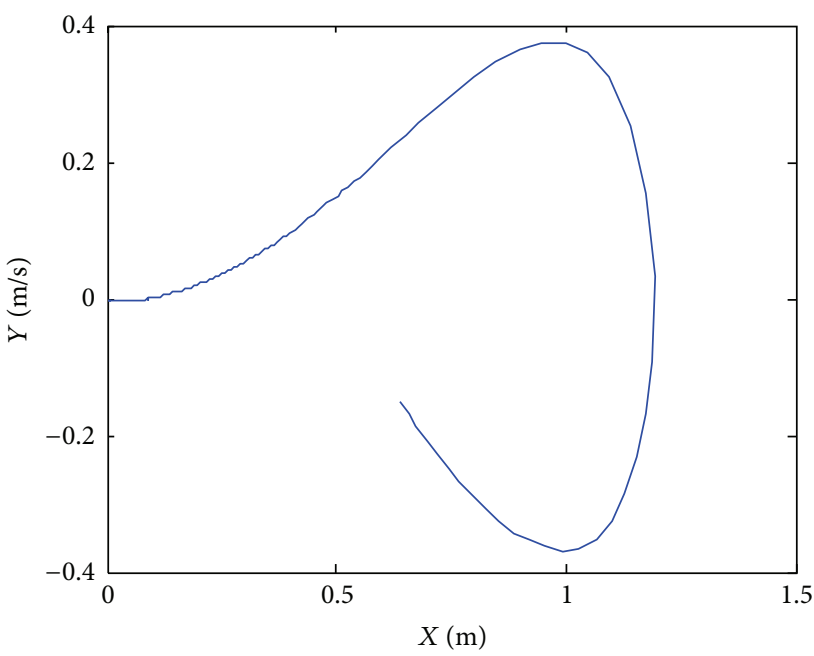

(c) Change amplitude 2

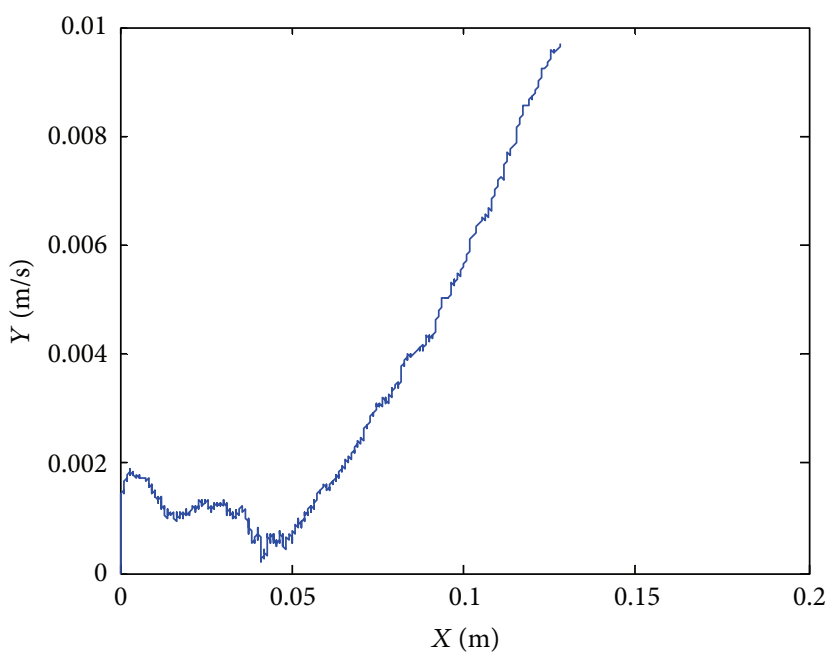

(b) Change amplitude 1

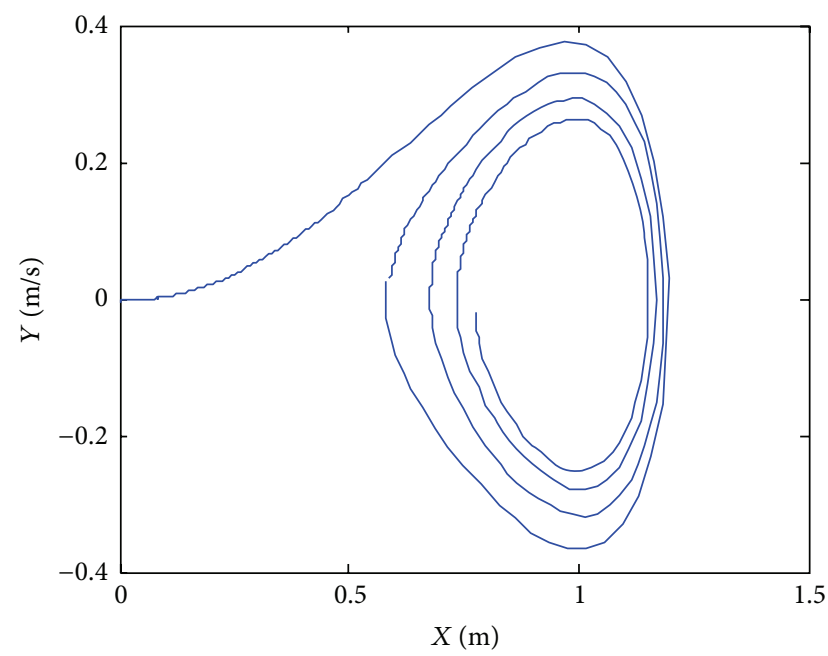

(d) No change

Figure 9: Phase trajectories of different signals.

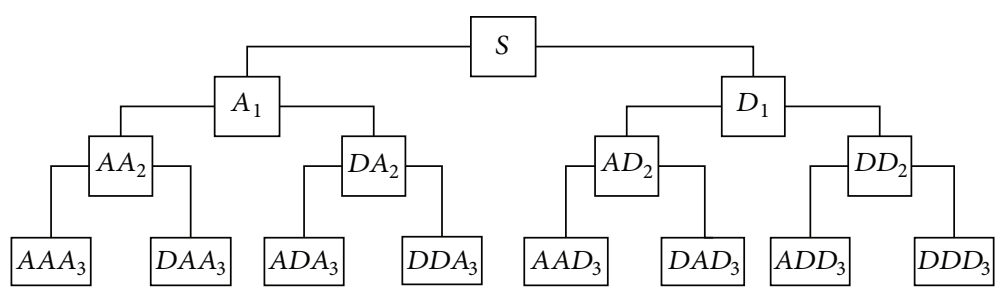

Figure 10: WPT decomposition structure.

TABLE 1: $M D_{C}$ and $D_{A}$ of Figure 12.

\begin{tabular}{lcc}
\hline State & $M D_{C}$ & $D_{A}$ \\
\hline PLC & 1.4690 & 0.0356 \\
CS & 1.4670 & 0.0061 \\
CLS & 0.0019 & 0.0002 \\
\hline
\end{tabular}

$M D_{C}$ value of CLS is very small, and its magnitude order stabilized near $z_{1}$ (in this paper, $z_{1}=10^{-3}$ ), but $M D_{C}$ of CS and PLS are both to stabilize near $z_{2}$ (in the paper, $z_{2}=1.4$ ). For CS and PLS, their $D_{A}$ has a larger difference. In order to distinguish CS and PLS accurately, $s_{j}$ is proposed $\left(s_{j}=\right.$ $M D_{C}-z_{2}$ ). While $\left|s_{j}\right|<a$ (in the paper, $a=0.1$ ), CS and 


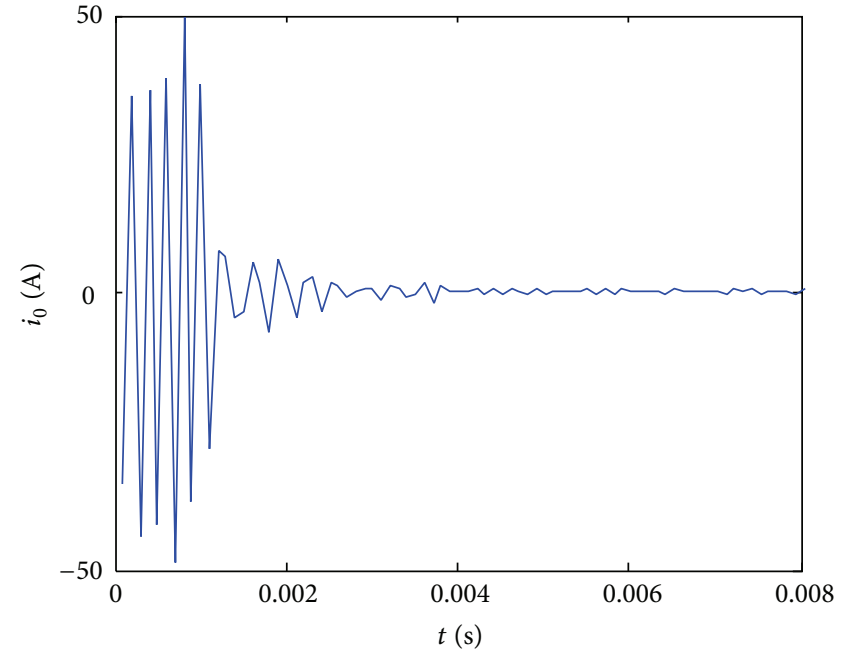

(a) Small faults resistance

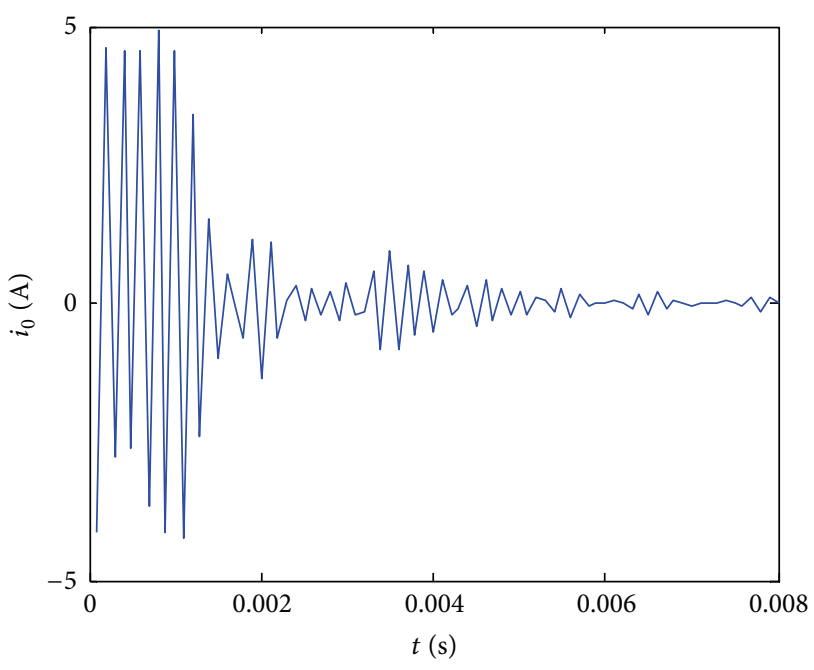

(b) Big faults resistance

FiguRE 11: CFB of different resistances.

PLS states cannot be distinguished by $M D_{C}$ solely. Therefore, it proposed $h_{j}$ :

$$
h_{j}=\frac{\max \left(D_{A j}\right)}{D_{A j}},
$$

where $\max \left(D_{A j}\right)$ is the maximum value of $D_{A}$ in all phase trajectories, $j$ is the number of phase trajectories.

If $h_{j}>b$ (in the paper $b=1.5$ ), the phase trajectory that has $\max \left(D_{A j}\right)$ is judged PLS, others are judged CS. If $h_{j} \leq b$, all phase trajectories are judged CS.

In addition, phase trajectory of magnitude order near the $z_{1}$ is judged CLS.

From above analysis, CLS, CS, and PLS can be accurately distinguished by $D_{A}$ and $M D_{C}$. When SPG fault occurs, CFB with detection factor is inputted to IOS, and it used $D_{A}$ and $M D_{C}$ to select the fault line. Therefore, the novel criterion of fault line selection method is proposed.

Step 1. If only one line has $\left|s_{j}\right|<a$ (this line is called $L$ ), and the phase trajectory magnitude of other lines stabilized near $z_{1}$. In other words, $L$ makes IOS turn to PLS or CS and other lines make IOS turn to CLS. Therefore, $L$ is judged as fault line and other lines are judged as healthy line.

Step 2. If many lines have $\left|s_{j}\right|<a$, calculated $h_{j}$, If $h_{j}>b$ ( $b=1.5$ ), the line with maximum $D_{A}$ makes IOS turn to PLS (this line is called $L$ ), other lines make IOS turn to CLS or CS. Therefore, $L$ is judged as fault line and other lines are judged as healthy line.

Step 3. If all lines do not comply with Steps 1 and 2 , the fault is judged as bus fault.

\section{Simulation and Verification}

6.1. Simulation Model. In this paper, SPG fault simulated by ATP-EMTP, and the simulation model is shown in Figure 13.
There are 4 lines, such as: $S_{1}, S_{2}, S_{3}$, and $S_{4}$; their lengths are $13.5 \mathrm{~km}, 24 \mathrm{~km}, 17 \mathrm{~km}$, and $10 \mathrm{~km}$, respectively. Simulation parameters are

Overhead Line. Positive-sequence parameters: $R_{1}=0.17$ $\Omega / \mathrm{km}, L_{1}=1.2 \mathrm{mH} / \mathrm{km}, C_{1}=9.697 \mathrm{nF} / \mathrm{km}$, zero-sequence parameters: $R_{0}=0.23 \Omega / \mathrm{km}, \quad L_{0}=5.48 \mathrm{mH} / \mathrm{km}, C_{0}=$ $6 \mathrm{nF} / \mathrm{km}$.

Cable Line. Positive-sequence parameters: $R_{11}=0.193 \Omega / \mathrm{km}$, $L_{11}=0.442 \mathrm{mH} / \mathrm{km}, C_{11}=143 \mathrm{nF} / \mathrm{km}$, zero-sequence parameters: $R_{00}=1.93 \Omega / \mathrm{km}, L_{00}=5.48 \mathrm{mH} / \mathrm{km}, C_{00}=$ $143 \mathrm{nF} / \mathrm{km}$.

Transformer. $110 / 10.5 \mathrm{kV}$, leakage impedances of high voltage side: $0.40+j 12.20 \Omega$, leakage impedances of low voltage side: $0.006+j 0.183 \Omega$, excitation current: $0.672 \mathrm{~A}$, magnetizing flux: $202.2 \mathrm{~Wb}$, magnetic resistance: $400 \mathrm{k} \Omega$.

Load. All are delta connected, $Z_{L}=400+j 20 \Omega$.

Arc Suppression Coil. $L_{N}=1281.9 \mathrm{mH}, R_{N}=40.2517 \Omega$.

6.2. SPG Fault Analysis. Set fault resistance and initial angle as equal to $0.0001 \Omega$, and $0^{\circ}$, respectively; fault line voltage of phases A, B, and C was shown in Figure 14, and each line zero-sequence current was shown in Figure 15.

It shows that phase voltage of healthy phases $\mathrm{B}$ and $\mathrm{C}$ are increasing and their amplitude is equal, but the phase voltage of fault phase A is equal to 0 approximately in Figure 14. This phenomenon meets the boundary condition of A phase to ground fault. Furthermore, all lines have same voltage value, because each line is linked with the same bus line in parallel connection. Therefore, this paper chose zerosequence current to study the fault line selection.

In Figure 15, when SPG fault occurs, zero-sequence current value of each line is not equal to 0 , its current waveforms 


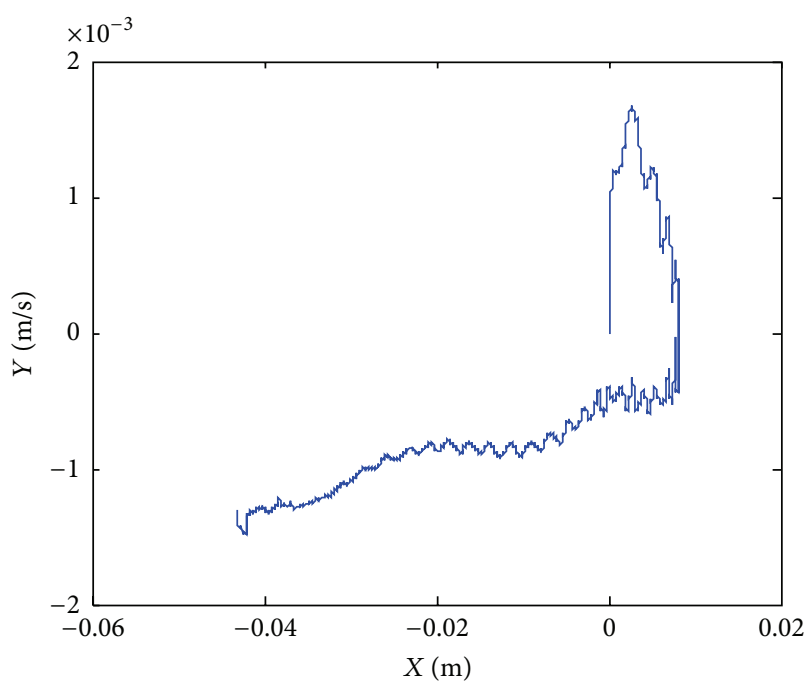

(a) Chaotic-like state

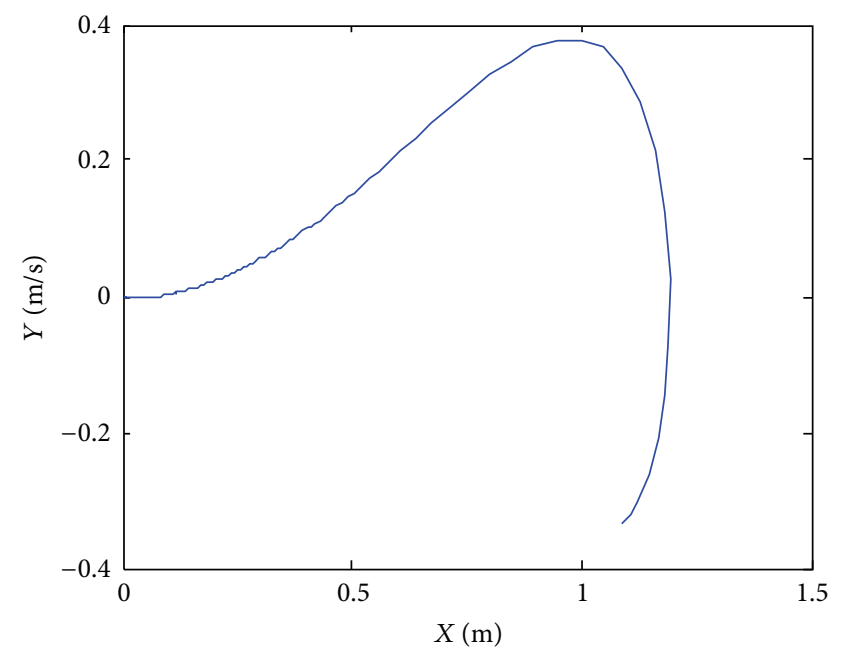

(c) Criticality state

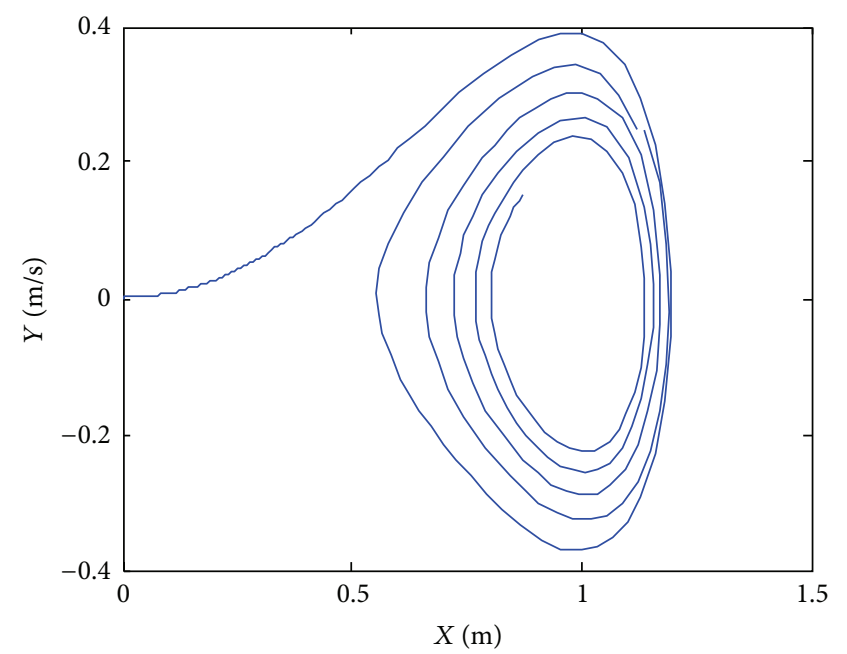

(e) Period-like state

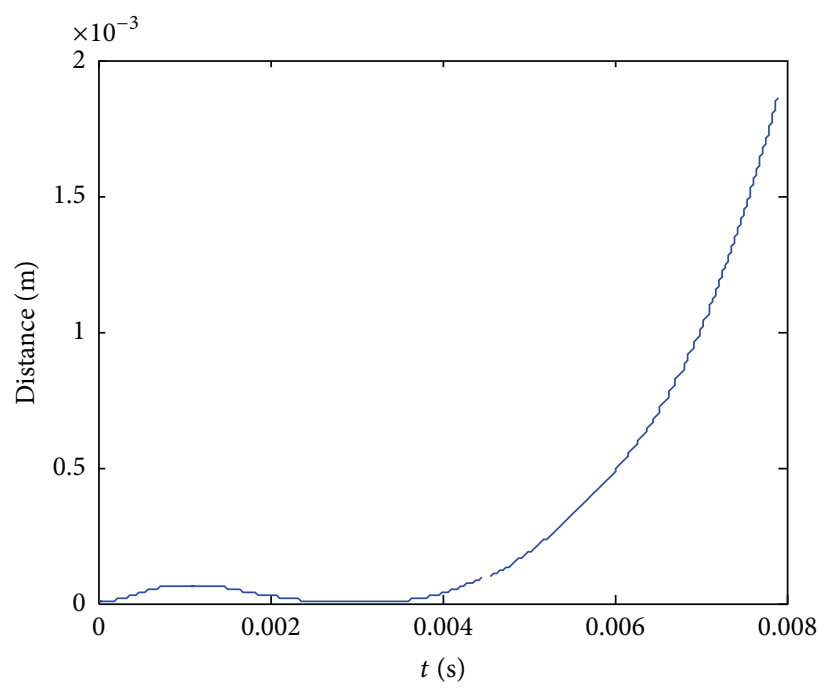

(b) Chaotic-like distance

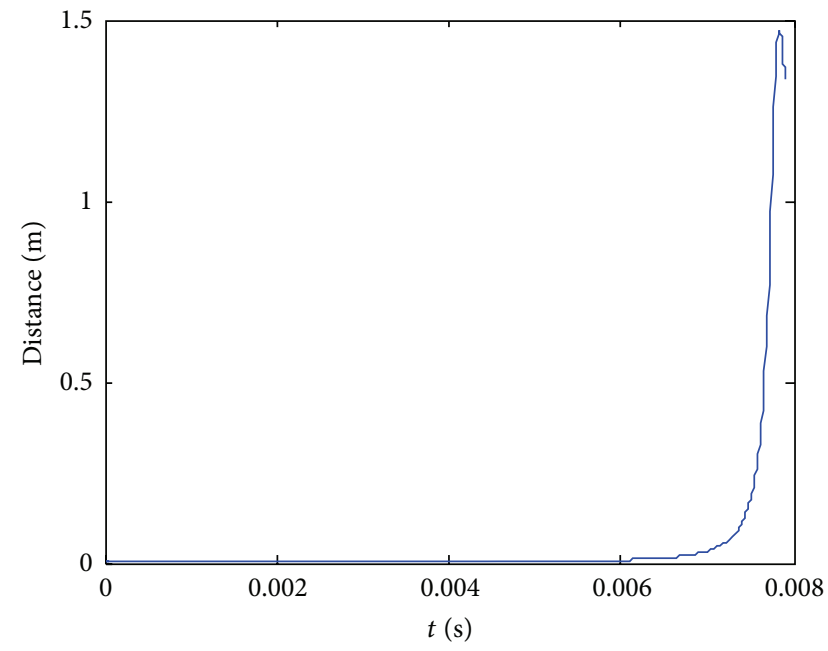

(d) Criticality distance

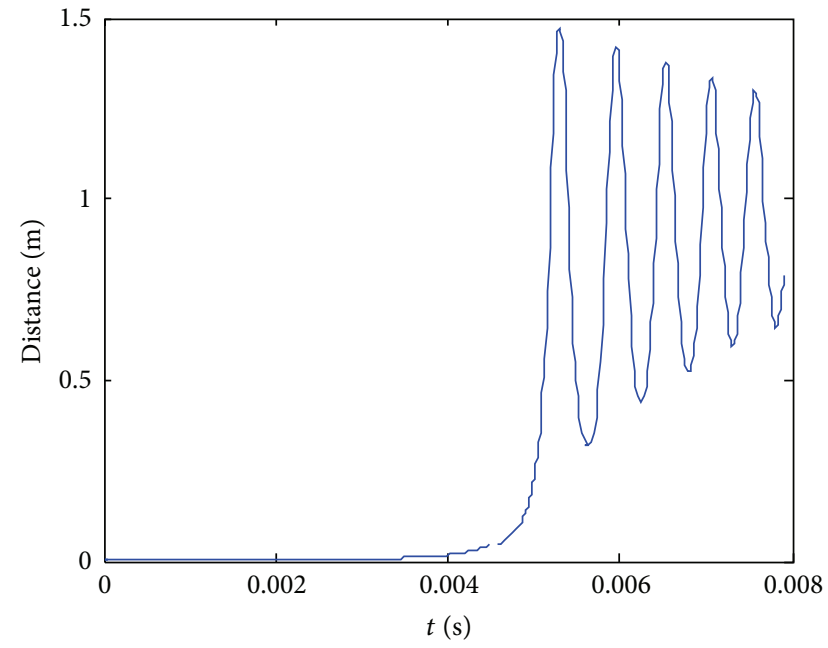

(f) Period-like distance

FIgURE 12: Chaotic distances of different states. 


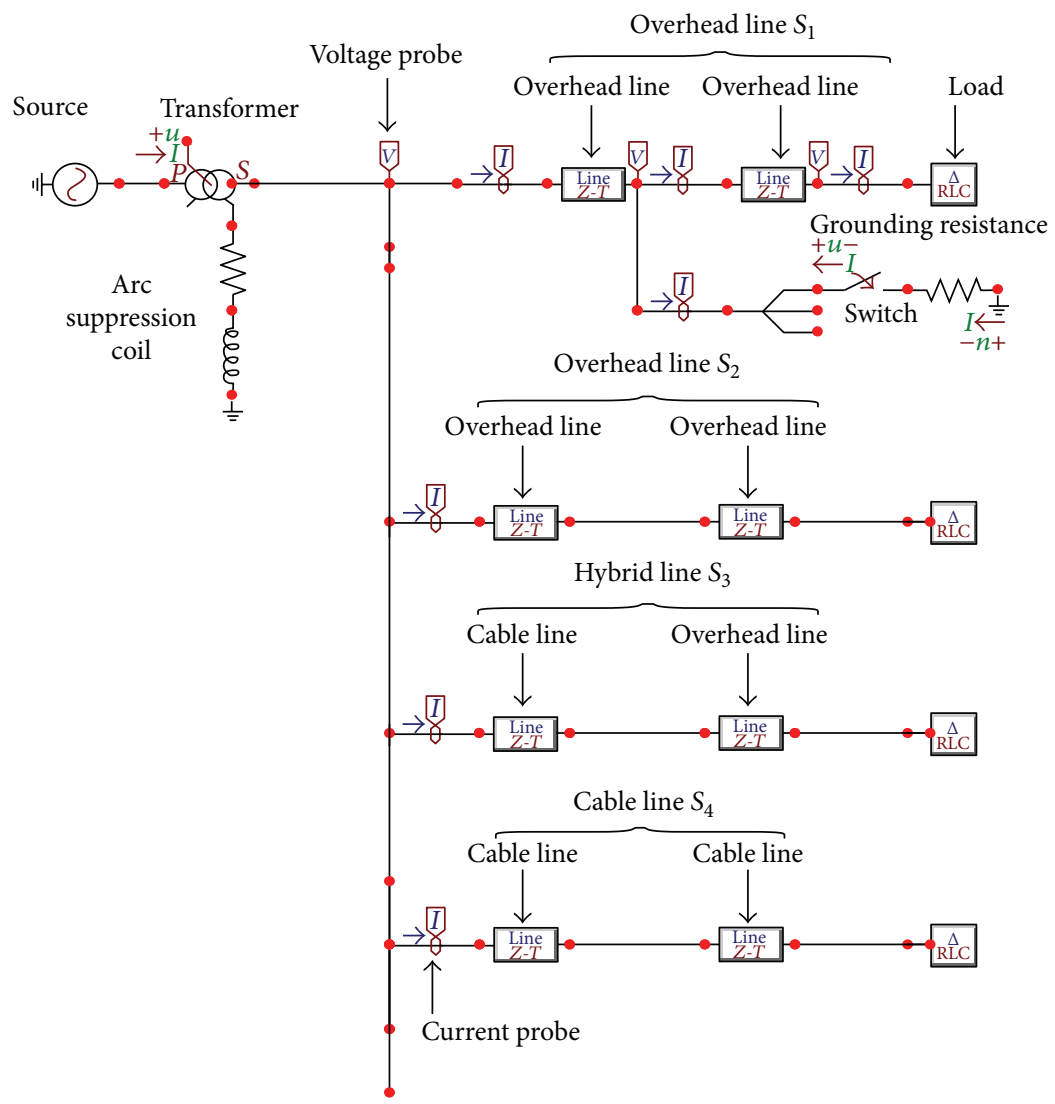

FIGURE 13: Simulation model of ATP-EMTP.

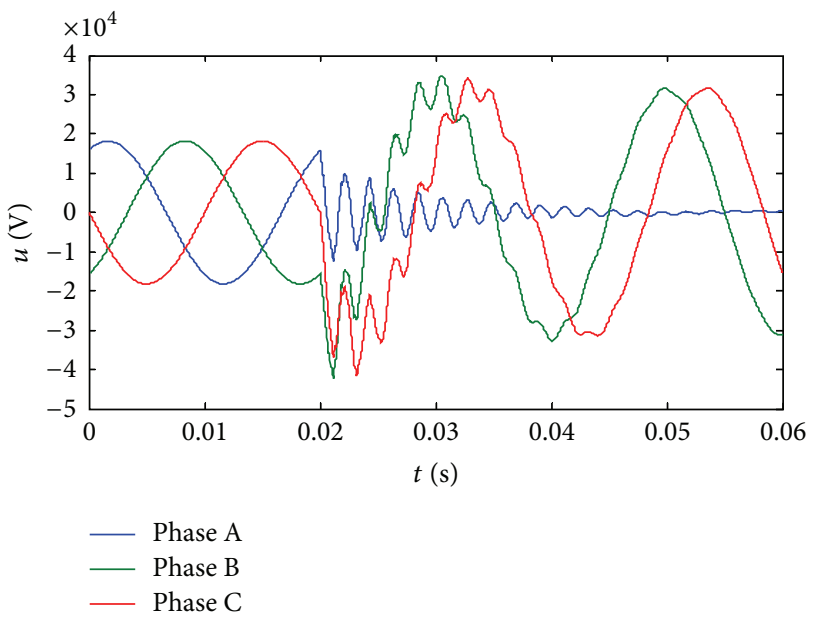

FIGURE 14: Phase voltage of fault line.

have damped oscillation state, and the attenuation speed is fast. The gap of zero-sequence current between fault line and healthy line is smaller after $0.03 \mathrm{~s}$, but the gap of TZSC between fault line and healthy line is larger in $0.02-0.03 \mathrm{~s}$. In addition, healthy line TZSC is similar. Therefore, TZSC is chosen to study fault line selection method in this paper.

6.3. Changing Initial Phase Angle and Resistance. When fault occurred in $S_{1}$, fault location is $5 \mathrm{~km}$ away from bus line, and the initial angles are $0^{\circ}, 30^{\circ}, 60^{\circ}$, and $90^{\circ}$ respectively.

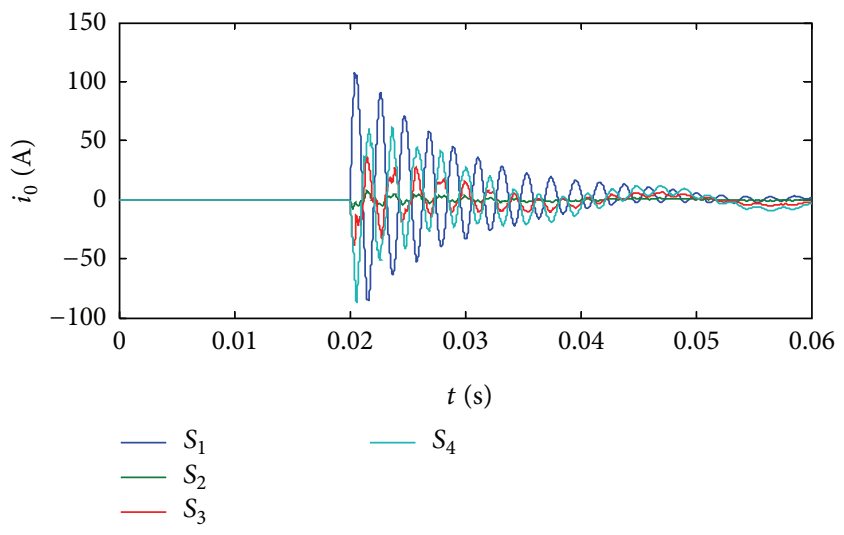

FIGURE 15: Zero-sequence current of each line.

Therefore, each TZSC of T/2 decomposed by db10 wavelet packet when fault occurred. According to paper [16], IOS parameters were set as $k=0.05, \gamma=0.002$, and $\beta=0.000286$.

To show phase trajectory difference, this paper gives 2 examples, one is that initial angle is equal to $30^{\circ}$ and fault resistance is equal to $1100 \Omega$, to express conveniently, this paper uses $\left(30^{\circ}, 1100 \Omega\right)$ to represent the fault condition; the other example is $\left(90^{\circ}, 2000 \Omega\right)$. The TZSC and CFB of the two examples were shown in Figures 16 and 17, respectively. 


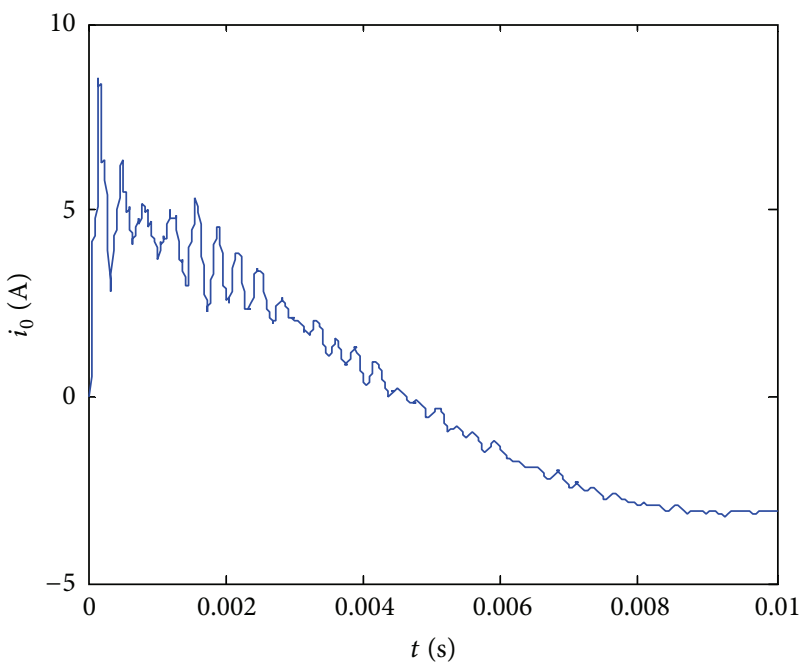

(a) Transient zero-sequence current

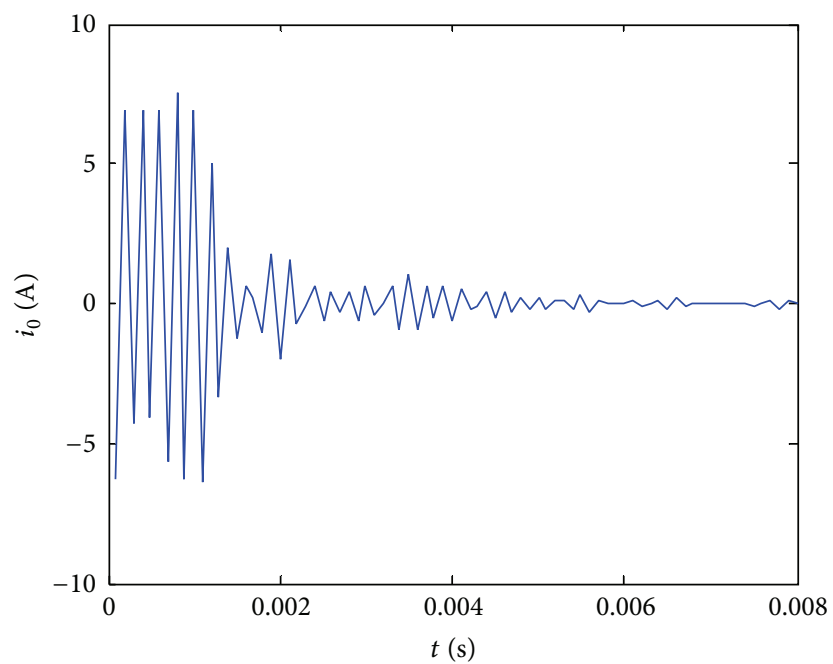

(b) Characteristic frequency band

Figure 16: No 1 of TZSC and CFB.

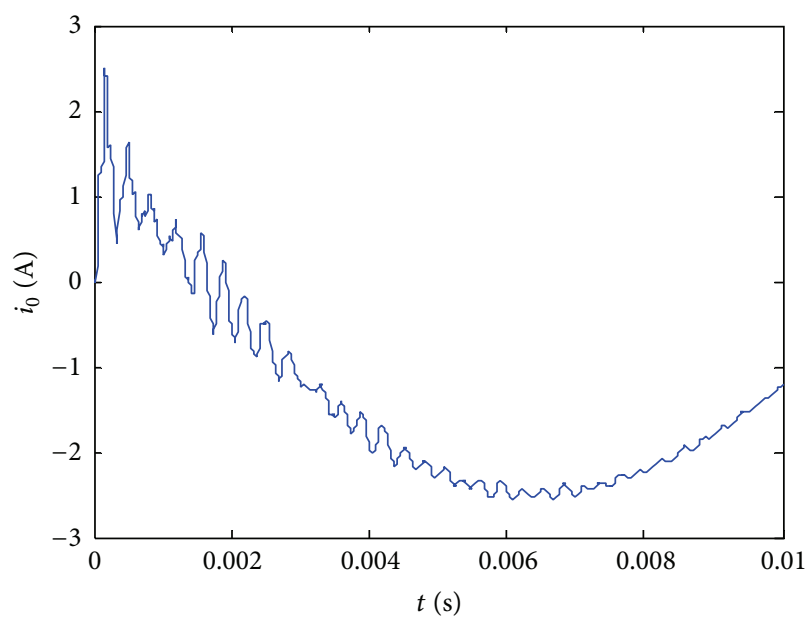

(a) Transient zero-sequence current

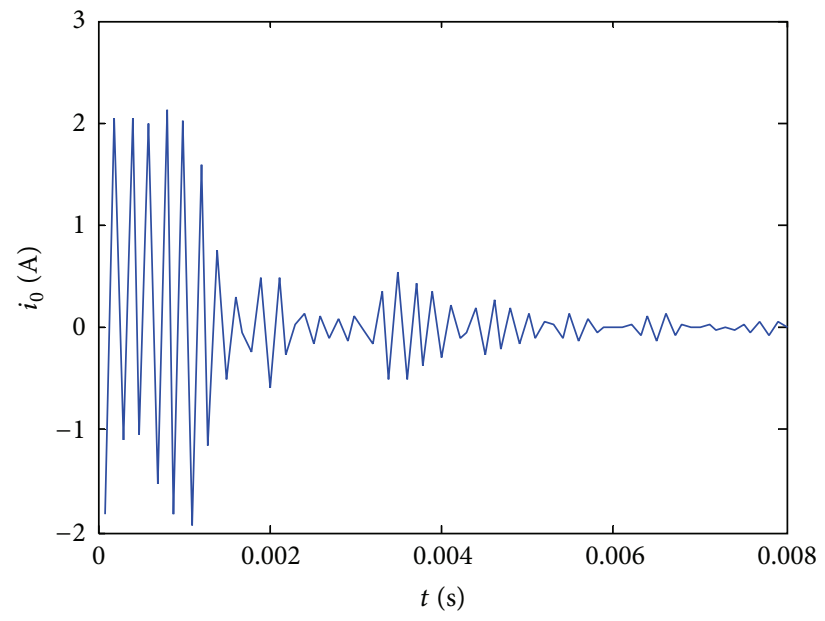

(b) Characteristic frequency band

FIgURE 17: No 2 of TZSC and CFB.

It shows that TZSC and CFB are both damped oscillation signal in Figures 16 and 17, different fault conditions have different oscillation damping degrees. Furthermore, CFB can describe time-frequency characteristics of transient signal more clearly in some frequency bands; it provides a basis for fault feature information processing [17]. Therefore, CFB is analyzed by IOS for fault line selection. According to new criterion, fault line selection result is shown in Table 2 .

Under the fault condition: $\left(30^{\circ}, 1100 \Omega\right)$, according to Table 2, $M D_{C}$ magnitude orders of $S_{3}$ and $S_{4}$ are both $10^{-3}$; it judges $S_{3}, S_{4}$ as healthy line. $s_{j}$ of $S_{1}$ and $s_{j}$ of $S_{2}$ are both less than 0.1; it indicated that $S_{1}, S_{2}$ are PLS or CS, combining $D_{A}, h_{j}=0.0356 / 0.0061=5.84>1.5$; therefore, $S_{1}$ makes phase trajectory turn to PLS, and $S_{2}$ makes phase trajectory turn to CS, which is same as Figure 18. Then, $S_{1}$ is judged as fault line; other lines are judged as healthy line.

Under the fault condition: $\left(90^{\circ}, 2000 \Omega\right)$, the $s_{j}$ of $S_{1}$ meets $s_{j}=1.4674-1.4=0.0674$, because $s_{j}$ is smaller than 0.1 and the $M D_{C}$ magnitude orders of other lines are all $10^{-3}$, it judges that $S_{1}$ makes IOS turn to PLS and other lines make IOS turn to CLS. Therefore, the $S_{1}$ is judged as fault line, and other lines are judged as healthy line. The selection result is the same as the simulation setting. It is as shown in Figure 19.

From above analysis, fault line selection results are same as simulation settings, which indicate that the method of this paper can adapt to different resistances and different phase angles.

6.4. Different Lines Fault. Refer to paper [18]; $S_{3}$ is hybrid line and $S_{4}$ is pure cable line, therefore, simulate the different lines occur fault, and the results are shown in Table 3. With cable lines taking part in simulation, TZSC decay process becomes shorter [16], but it does not affect fault line selection results. Table 3 shows that the method has better results when different lines fault occurred. 
TABLE 2: Fault line selection results of different resistances and angles.

\begin{tabular}{|c|c|c|c|c|c|c|c|}
\hline Fault line & Fault situation & $\begin{array}{c}\text { Distance of phase } \\
\text { trajectory }\end{array}$ & $S_{1}$ & $S_{2}$ & $S_{3}$ & $S_{4}$ & Selection result \\
\hline \multirow{14}{*}{$S_{1}$} & $\left(30^{\circ}, 90 \Omega\right)$ & $M D_{C}$ & 1.4666 & 0.0005 & 0.0006 & 0.0017 & $S_{1}$ \\
\hline & \multirow{2}{*}{$\left(0^{\circ}, 400 \Omega\right)$} & $M D_{C}$ & 1.4691 & 1.4718 & 0.0005 & 0.0029 & \multirow{2}{*}{$S_{1}$} \\
\hline & & $D_{A}$ & 0.0598 & 0.0072 & 0.0001 & 0.0004 & \\
\hline & $\left(0^{\circ}, 2000 \Omega\right)$ & $M D_{C}$ & 1.4689 & 0.0013 & 0.0005 & 0.0007 & $S_{1}$ \\
\hline & $\left(30^{\circ}, 400 \Omega\right)$ & $M D_{C}$ & 1.4679 & 0.0004 & 0.0019 & 0.0053 & $S_{1}$ \\
\hline & \multirow{2}{*}{$\left(30^{\circ}, 1100 \Omega\right)$} & $\mathrm{MD}_{\mathrm{C}}$ & 1.4690 & 1.4670 & 0.0014 & 0.0019 & \multirow{2}{*}{$\mathrm{S}_{1}$} \\
\hline & & $\mathbf{D}_{\mathrm{A}}$ & 0.0356 & 0.0061 & 0.0002 & 0.0003 & \\
\hline & $\left(30^{\circ}, 2000 \Omega\right)$ & $M D_{C}$ & 1.4701 & 0.0035 & 0.0005 & 0.0012 & $S_{1}$ \\
\hline & $\left(60^{\circ}, 90 \Omega\right)$ & $M D_{C}$ & 1.4667 & 0.0006 & 0.0009 & 0.0060 & $S_{1}$ \\
\hline & \multirow{2}{*}{$\left(60^{\circ}, 400 \Omega\right)$} & $M D_{\mathrm{C}}$ & 1.4663 & 1.4668 & 0.3589 & 0.0043 & \multirow{2}{*}{$S_{1}$} \\
\hline & & $D_{A}$ & 0.0521 & 0.0088 & 0.0030 & 0.0007 & \\
\hline & $\left(60^{\circ}, 2000 \Omega\right)$ & $M D_{C}$ & 1.4677 & 0.0024 & 0.0005 & 0.0006 & $S_{1}$ \\
\hline & $\left(90^{\circ}, 400 \Omega\right)$ & $M D_{C}$ & 1.4650 & 0.0014 & 0.0005 & 0.0019 & $S_{1}$ \\
\hline & $\left(90^{\circ}, 2000 \Omega\right)$ & $M D_{C}$ & 1.4674 & 0.0004 & 0.0015 & 0.0006 & $S_{1}$ \\
\hline
\end{tabular}

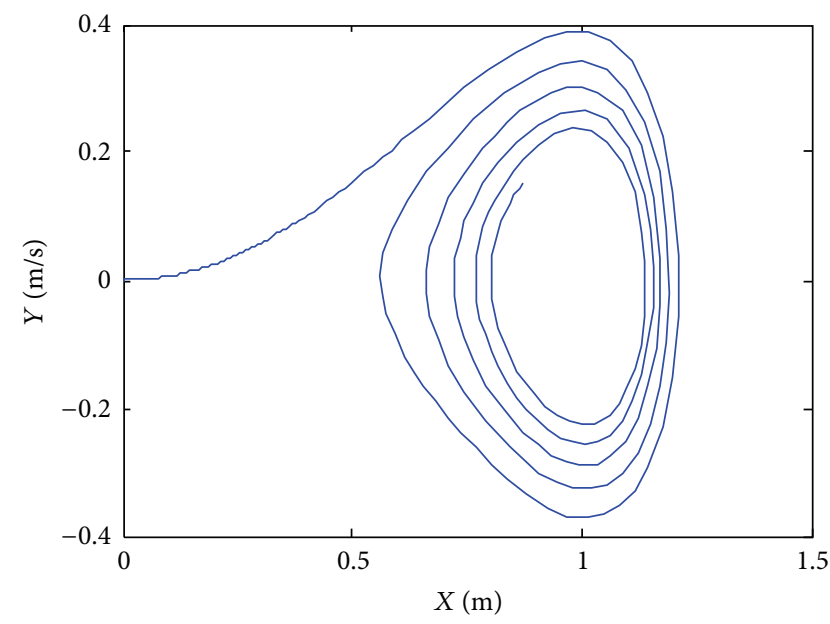

(a) $S_{1}$

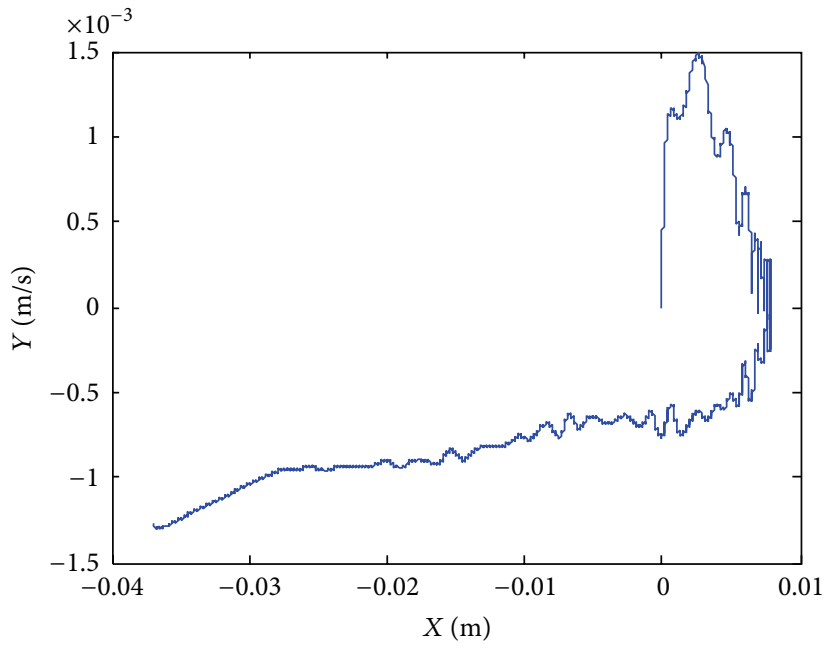

(c) $S_{3}$

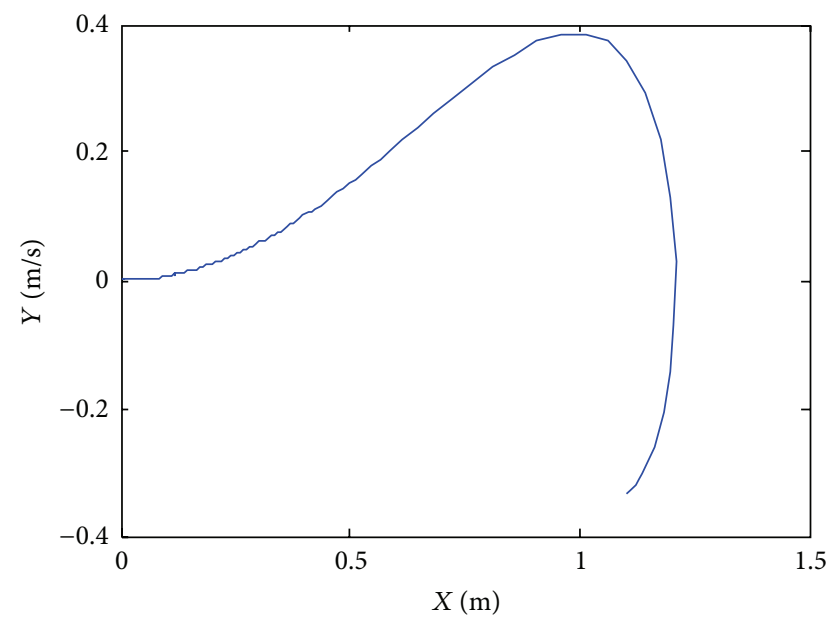

(b) $S_{2}$

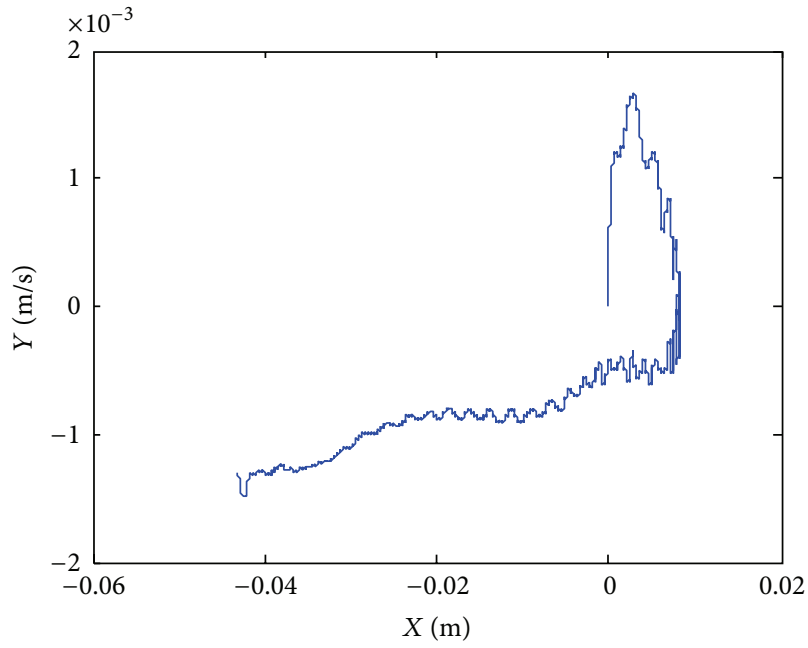

(d) $S_{4}$

Figure 18: Phase trajectory of $\left(30^{\circ}, 1100 \Omega\right)$. 


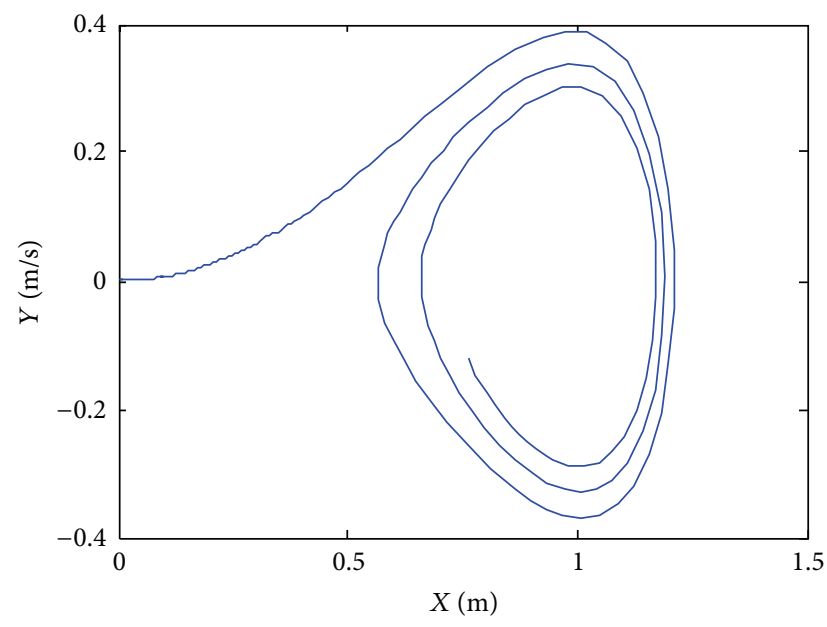

(a) $S_{1}$

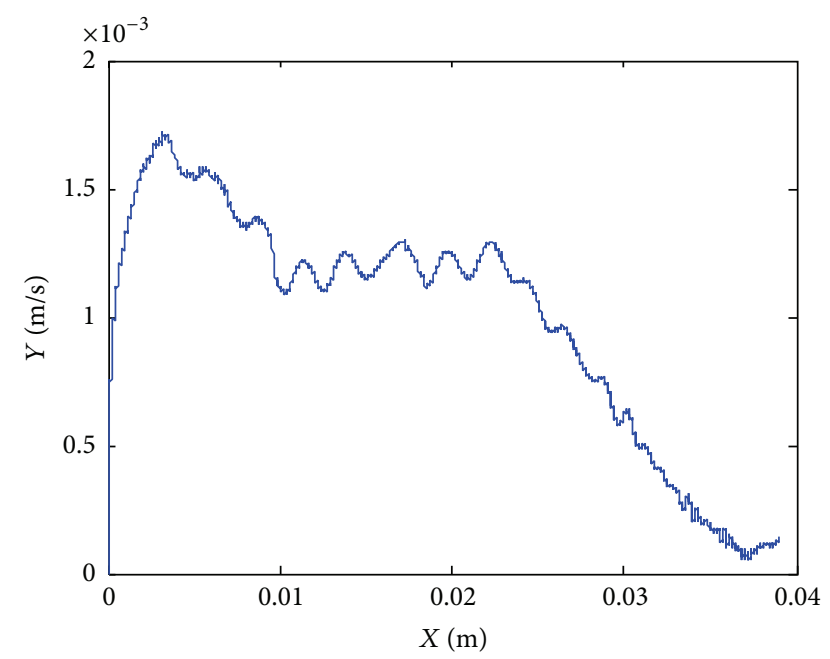

(c) $S_{3}$

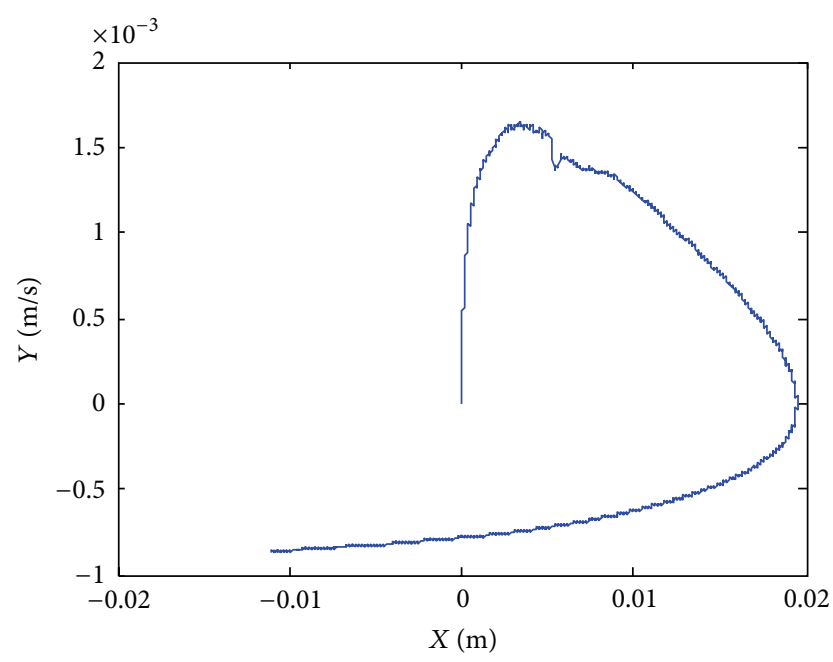

(b) $S_{2}$

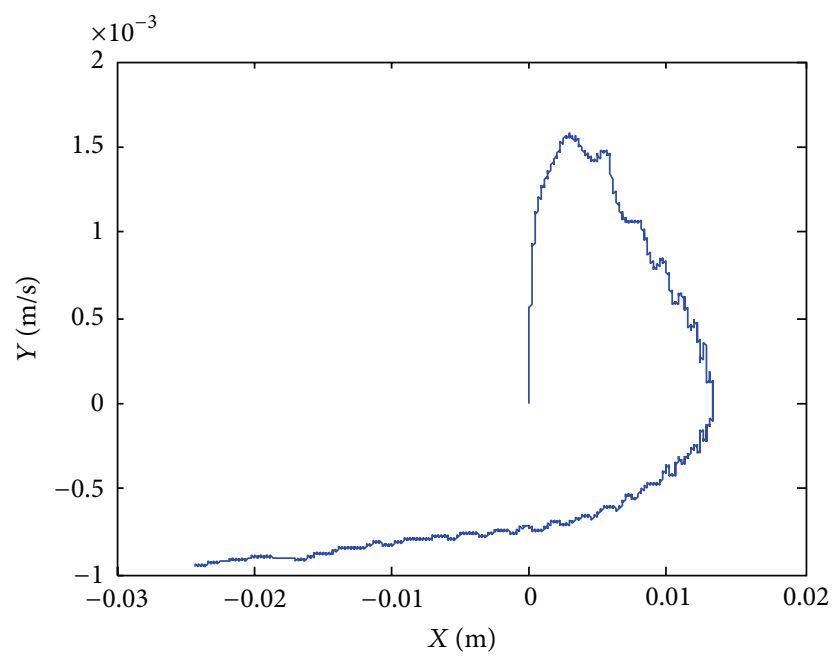

(d) $S_{4}$

FIgURE 19: Phase trajectory of $\left(90^{\circ}, 2000 \Omega\right)$.

6.5. Fault with Strong Noise. Considering actual fault situation, fault signal usually has noise; therefore, add $0.5 \mathrm{db}$ random Gaussian white noise to TZSC to validate the method's noise immunity. The waveform was shown in Figure 20, it shows that the TZSC signal is covered by noise completely. Fault line selection results are shown in Table 4.

Under various fault conditions, the proposed method can also achieve better result, and it indicates that the method has good noise immunity. Furthermore, the fault line selection result is better than paper [19] which adds $20 \mathrm{db}$ noise.

6.6. Different Distances Fault. In fact, fault location has different distances from bus line when fault occurs. In Section 6.6, simulate $S_{1}$ line with different distance fault, and the fault resistance is $300 \Omega$, fault distances are $5 \mathrm{~km}, 30 \mathrm{~km}, 35 \mathrm{~km}$, $40 \mathrm{~km}$, and $45 \mathrm{~km}$, respectively. Fault line selection results are shown in Table 5.
According to Table 5, the result is same as simulation setting, which indicates that the proposed method adapts to different distance faults.

\section{Nondetection Zone of Proposed Method}

7.1. Small Resistance to Ground Fault. Set fault resistance between $0 \Omega$ and $80 \Omega$. According to proposed method, partial results of fault line selection are shown in Table 6.

The proposed method in this paper does not work for small resistance to ground fault in Table 6. In addition, when fault resistance value is bigger than $10 \Omega$, cable line and cable hybrids line usually make IOS turn to PLS, and overhead line makes IOS turn to CLS, but when fault resistance value is smaller than $10 \Omega$, overhead line can also make IOS turn to PLS; for example, the fault condition is $\left(0^{\circ}, 5 \Omega\right)$. To express result obviously, phase trajectory of $\left(0^{\circ}, 10 \Omega\right)$ is given in Figure 21. 
TABLE 3: Different lines fault result.

\begin{tabular}{cccccccc}
\hline Fault line & Fault situation & Distance of phase trajectory & $S_{1}$ & $S_{2}$ & $S_{3}$ & $S_{4}$ & Selection result \\
\hline \multirow{3}{*}{$S_{4}$} & $\left(0^{\circ}, 200 \Omega\right)$ & $M D_{C}$ & 0.0009 & 1.4187 & 1.4681 & 1.4678 & $S_{4}$ \\
& $\left(0^{\circ}, 700 \Omega\right)$ & $D_{A}$ & 0.0006 & 0.0048 & 0.0090 & 0.0863 & $S_{4}$ \\
& $\left(0^{\circ}, 2000 \Omega\right)$ & $M D_{C}$ & 0.0006 & 0.0845 & 0.0090 & 1.4684 & $S_{4}$ \\
\hline \multirow{3}{*}{$S_{3}$} & $\left(0^{\circ}, 200 \Omega\right)$ & $M D_{C}$ & 0.0007 & 0.0004 & 0.0004 & 1.4658 & 0.1994 \\
& $\left(0^{\circ}, 700 \Omega\right)$ & $M D_{C}$ & 0.0007 & 0.0777 & 1.4648 & $S_{3}$ \\
& $\left(0^{\circ}, 2000 \Omega\right)$ & $M D_{C}$ & 0.0016 & 0.0009 & 1.4692 & 0.0027 & $S_{3}$ \\
& & $M D_{C}$ & 0.0003 & 1.4664 & 1.4691 & 0.1934 & $S_{3}$ \\
\hline
\end{tabular}

TABLE 4: Strong noise fault results.

\begin{tabular}{lccccccc}
\hline Fault line & Fault situation & Distance of phase trajectory & $S_{1}$ & $S_{2}$ & $S_{3}$ & $S_{4}$ & Selection result \\
\hline \multirow{3}{*}{$S_{1}$} & $\left(30^{\circ}, 90 \Omega\right)$ & $M D_{C}$ & 1.4684 & 0.0002 & 0.0005 & 0.0006 & $S_{1}$ \\
& $\left(0^{\circ}, 200 \Omega\right)$ & $M D_{C}$ & 1.4667 & 0.0004 & 0.0003 & 0.0018 & $S_{1}$ \\
\hline \multirow{3}{*}{$S_{3}$} & $\left(0^{\circ}, 2000 \Omega\right)$ & $M D_{C}$ & 1.4689 & 0.0013 & 0.0005 & 0.0007 & $S_{1}$ \\
& $\left(0^{\circ}, 200 \Omega\right)$ & $M D_{C}$ & 0.0007 & 0.0777 & 1.4648 & 0.1994 & $S_{3}$ \\
& $\left(0^{\circ}, 2000 \Omega\right)$ & $M D_{C}$ & 0.0003 & 1.4664 & 1.4691 & 0.1934 & $S_{3}$ \\
\hline \multirow{3}{*}{$S_{4}$} & $\left(0^{\circ}, 200 \Omega\right)$ & $D_{A}$ & 0.0001 & 0.0069 & 0.0126 & 0.0028 & 1.4678 \\
& $\left(0^{\circ}, 2000 \Omega\right)$ & $D_{C}$ & 0.0009 & 1.4187 & 1.4681 & $S_{4}$ \\
& & $M D_{C}$ & 0.0006 & 0.0048 & 0.0090 & 0.0863 & \\
\hline
\end{tabular}

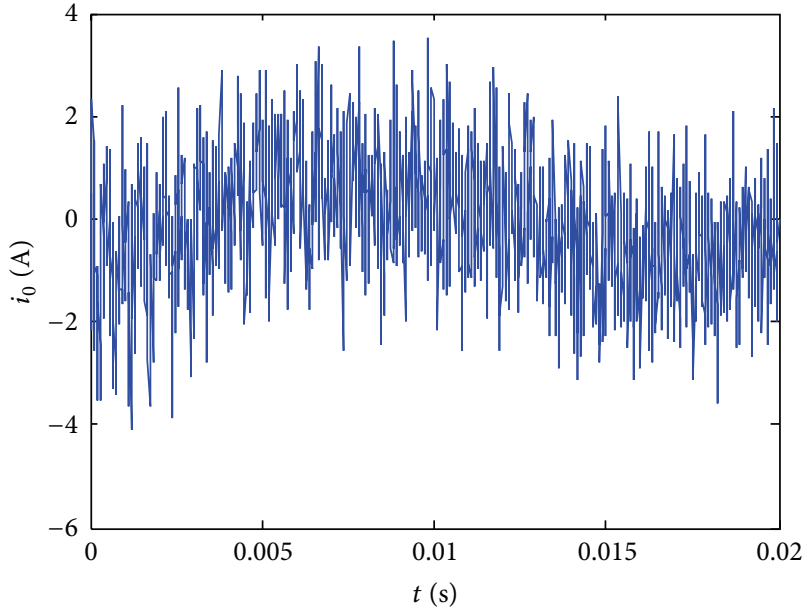

FIgURE 20: TZSC with $0.5 \mathrm{db}$ noise.

It shows that $S_{1}$ makes IOS turn to CS, $S_{2}$ makes IOS turn to CLS, $S_{3}$, and $S_{4}$ make IOS turn to PLS in Figure 21; it contradicts the proposed criterion in this paper (Steps 1, 2, and 3 ). The reason is that fault signal amplitudes are large and damped oscillation states are obvious in this fault situation, it makes all total driving force of IOS too large. There are two conditions, one is that fault line makes IOS directly cross PLS and turn to CLS, the other is that healthy line makes IOS directly cross CLS and turn to PLS or remain CLS. When fault resistance continues to decrease, fault line and healthy line can both make IOS turn to PLS, such as, fault condition: $\left(0^{\circ}\right.$, $5 \Omega$ ). In a word, the most essential thing is that the detection factor is determined by experiment, and it is not suitable for small resistance to ground fault.

7.2. High Resistance to Ground Fault at the End of Line. The length of $S_{1}$ is $13.5 \mathrm{~km}$, simulate fault location at the end of $S_{1}$, and fault resistance is set to $1.5 \mathrm{k} \Omega$ to $2 \mathrm{k} \Omega$. Its result is shown in Table 7.

According to Table 7, when each line CFB was solved by IOS, the healthy line usually makes IOS turn to PLS or CS, and fault line makes IOS turn to CLS, the phase trajectory of $\left(0^{\circ}, 1900 \Omega\right)$ is shown in Figure 22.

It is indicated that $S_{1}$ makes IOS turn to CLS, $S_{2}$ makes IOS turn to CS, and $S_{3}$ and $S_{4}$ make IOS turn to PLS in Figure 22. This result contradicts the proposed criterion in this paper (Steps 1, 2, and 3). This condition occurs due to the fact that fault location is in the end of line, and the fault resistance is larger. It makes voltage and current decrease and the fault current signal become weaker. Therefore, the proposed method is not suitable for this fault condition.

In conclusion, the proposed method is not suitable for small resistance or high resistance to ground fault in this paper; in other words, detection factor has a range, so how to choose better detection factor to adapt extensive fault conditions is to be further studied.

\section{Conclusions}

SPG fault line selection method based on IOS is proposed in this paper, and the conclusions are as follows.

(1) IOS has a better recognition for TZSC signal, to a certain extent; it makes up for deficiency of the duffing 


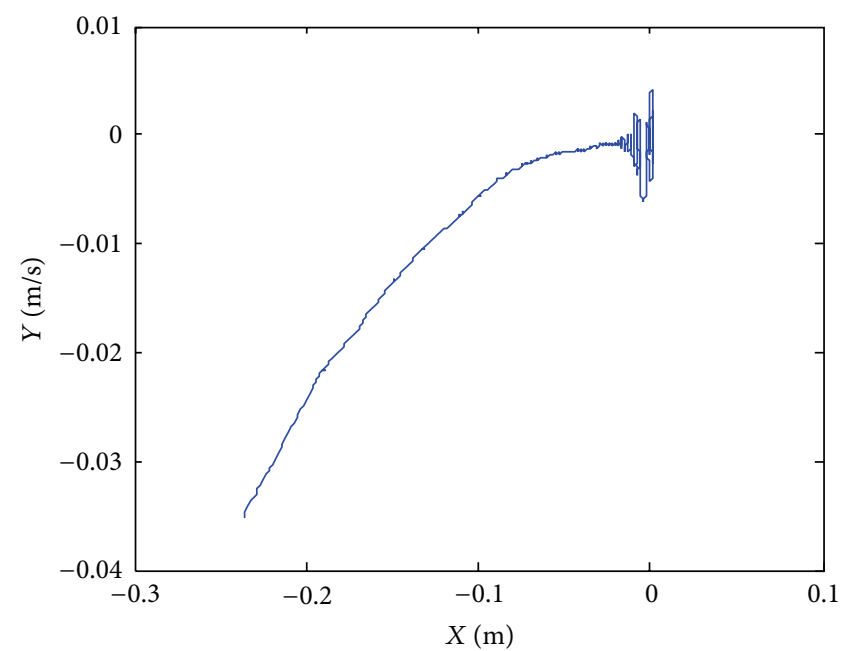

(a) $S_{1}$

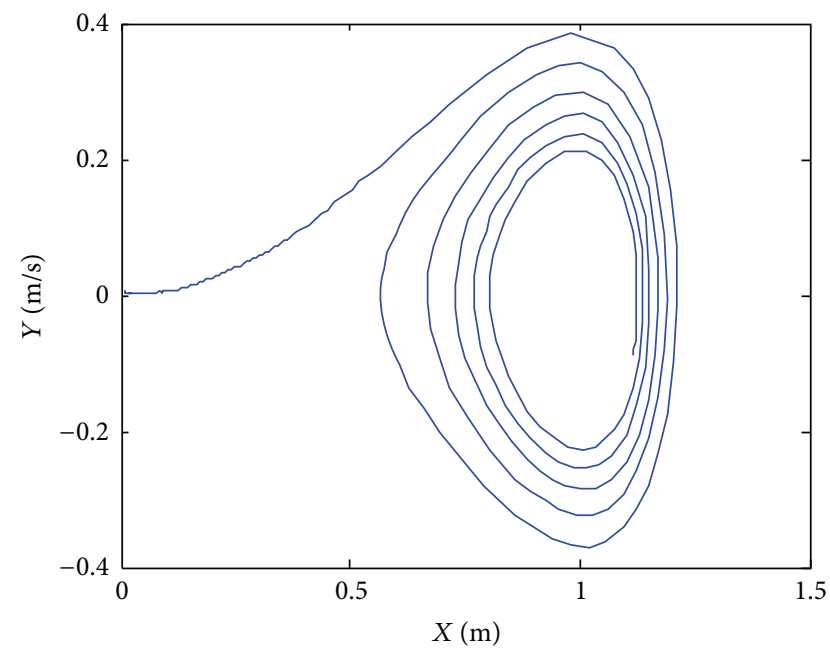

(c) $S_{3}$

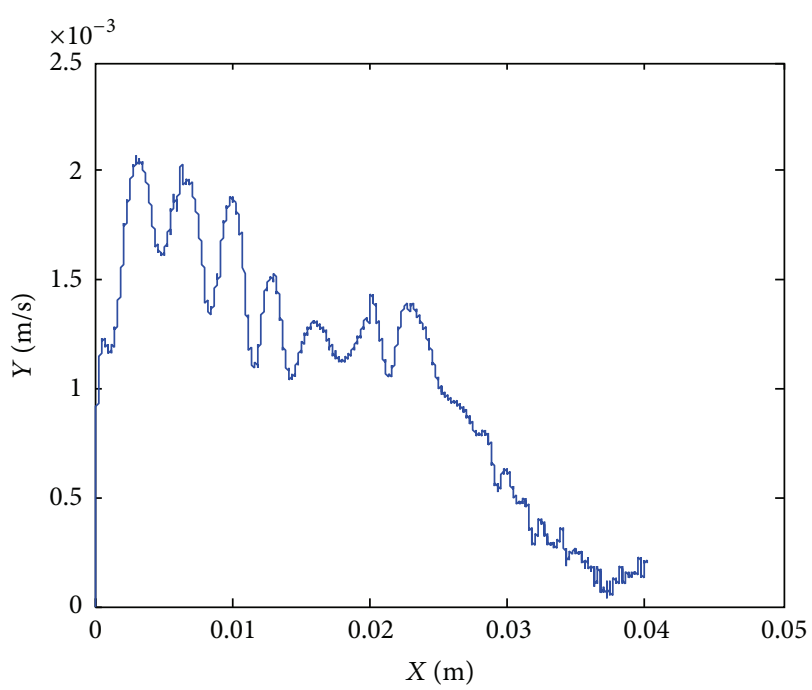

(b) $S_{2}$

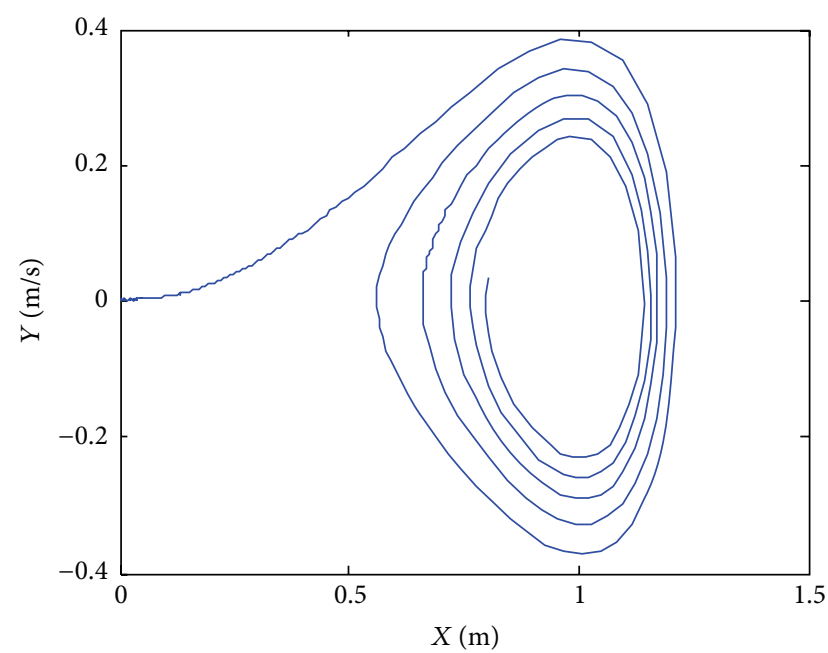

(d) $S_{4}$

FIGURE 21: Phase trajectory of $\left(0^{\circ}, 10 \Omega\right)$.

TABLE 5: Different distance fault results.

\begin{tabular}{cccccccc}
\hline Fault line & Fault situation & Distance of phase trajectory & $S_{1}$ & $S_{2}$ & $S_{3}$ & $S_{4}$ & Selection result \\
\hline & $\left(0^{\circ}, 300 \Omega, 5 \mathrm{~km}\right)$ & $M D_{C}$ & 0.0009 & 1.4187 & 1.4681 & 1.4678 & $S_{1}$ \\
& $\left(0^{\circ}, 300 \Omega, 10 \mathrm{~km}\right)$ & $M D_{C}$ & 1.4690 & 0.0004 & 1.4665 & 0.0022 & $S_{1}$ \\
& & $D_{A}$ & 0.0583 & 0.0002 & 0.0061 & 0.0004 & \\
$S_{1}$ & $\left(0^{\circ}, 300 \Omega, 30 \mathrm{~km}\right)$ & $M D_{C}$ & 0.3808 & 0.0007 & 0.0288 & 0.0005 & $S_{1}$ \\
& $\left(0^{\circ}, 300 \Omega, 35 \mathrm{~km}\right)$ & $M D_{C}$ & 1.4692 & 0.0003 & 1.3629 & 0.0004 & $S_{1}$ \\
& $\left(0^{\circ}, 300 \Omega, 40 \mathrm{~km}\right)$ & $M D_{C}$ & 1.4687 & 0.0011 & 1.4687 & 0.0003 & $S_{1}$ \\
& & $D_{A}$ & 0.0274 & 0.0008 & 0.0154 & 0.0005 & \\
\hline
\end{tabular}

chaotic oscillator which did not detect oscillation damping signal. In addition, TZSC signal decomposed by db10 wavelet packet, it decreased CFB quantities, and improved IOS solving speed.

(2) PLS phase trajectory can be seen as a circular movement with reduced radius; $\mathrm{CS}$ phase trajectory can be seen as a curve segment far away from origin point, but CLS phase trajectory is generally seen as chaotic state of movement. In addition, the $M D_{C}$ of CS is similar to PLS, and their value difference usually is about 0.1. But the $D_{A}$ between CS and PLS has a significant gap which usually is equal to 1.5 for their ratio. Therefore, phase trajectory state is usually judged by 


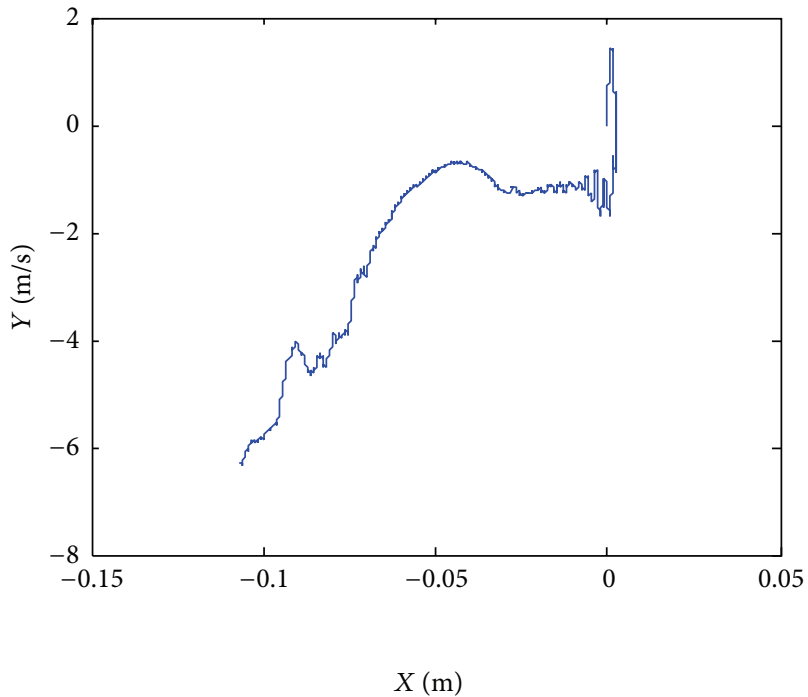

(a) $S_{1}$

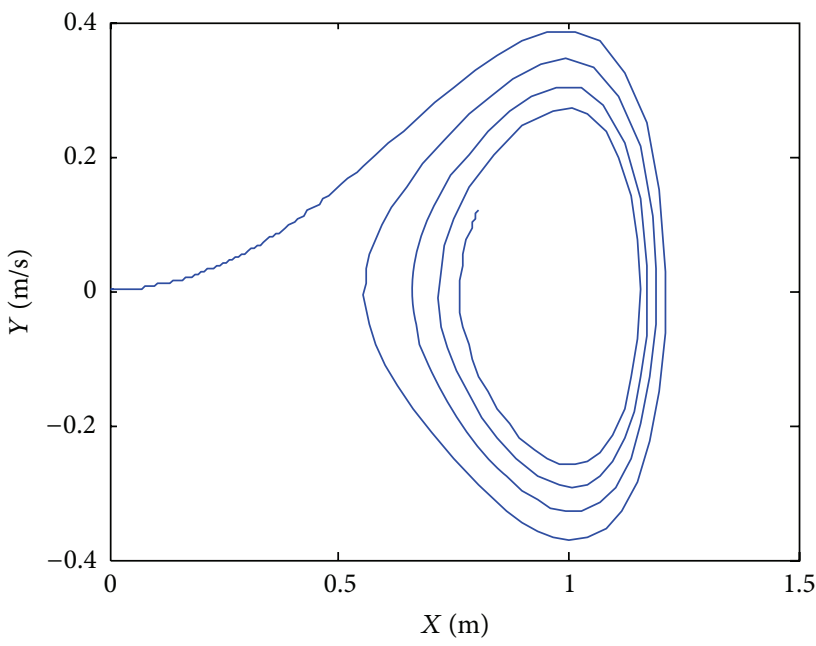

(c) $S_{3}$

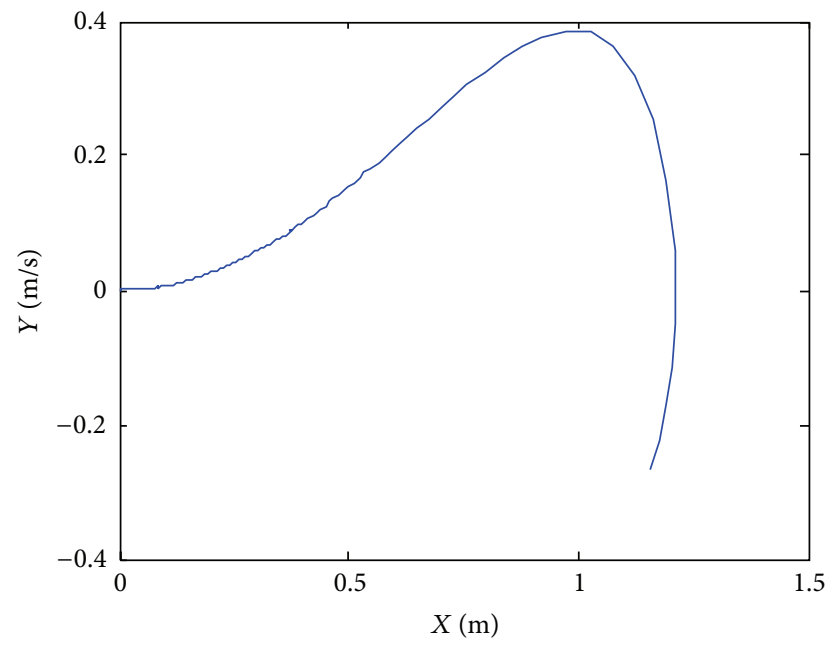

(b) $S_{2}$

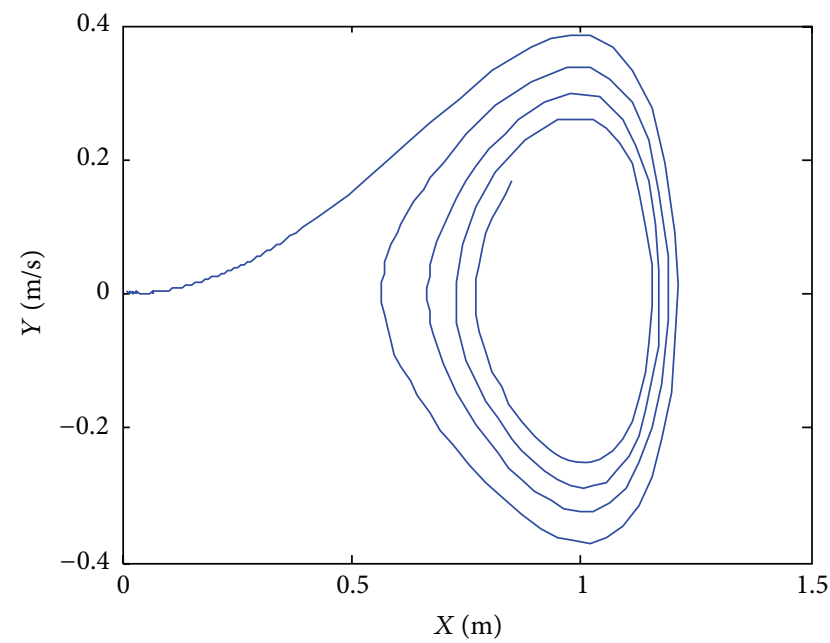

(d) $S_{4}$

FIgURE 22: Phase trajectory of $\left(0^{\circ}, 1900 \Omega\right)$.

TABLE 6: Small resistance to ground fault result.

\begin{tabular}{cccccccc}
\hline Fault line & Fault situation & Distance of phase trajectory & $S_{1}$ & $S_{2}$ & $S_{3}$ & $S_{4}$ & Selection result \\
\hline & $\left(0^{\circ}, 5 \Omega\right)$ & $M D_{C}$ & 1.4675 & 1.4643 & 1.4663 & 1.4677 & Failure \\
& & $D_{A}$ & 0.0127 & 0.0126 & 0.0379 & 0.0366 & \\
& & $M D_{C}$ & 0.0571 & 0.0016 & 1.4677 & 1.4704 & Failure \\
$S_{1}$ & $\left.D_{A}, 10 \Omega\right)$ & $M D_{C}$ & 0.0024 & 0.0010 & 0.0393 & 0.0359 & 0.0004 \\
& & $M D_{C}$ & 0.0006 & 0.0005 & 1.4654 & Failure \\
& $\left(0^{\circ}, 30 \Omega\right)$ & $M D_{C}$ & 0.0003 & 0.0007 & 1.4644 & 0.0030 & Failure \\
& $\left(0^{\circ}, 60 \Omega\right)$ & 0.0024 & 0.0003 & 0.0008 & 0.0021 & Failure \\
\hline
\end{tabular}

$D_{A}$, and $M D_{C}$ of CLS is very small. Besides, magnitude order of $M D_{C}$ is to stabilize at $10^{-3}$ for CLS.

(3) There are some nondetection zones of the proposed method: detection factor is determined by experiment, it can cause some errors, and the method has problem of insufficient sensitivity when small and high resistance to ground occur fault.

\section{Notations}

SPG: Single phase to ground

TZSC: Transient zero-sequence current

CFB: Characteristic frequency band

SVM: Support vector machine

IOS: Improved oscillator system 
TABLE 7: High resistance to ground fault result.

\begin{tabular}{|c|c|c|c|c|c|c|c|}
\hline Fault line & Fault situation & Distance of phase trajectory & $S_{1}$ & $S_{2}$ & $S_{3}$ & $S_{4}$ & Selection result \\
\hline \multirow{9}{*}{$S_{1}$} & \multirow{2}{*}{$\left(0^{\circ}, 1500 \Omega\right)$} & $M D_{C}$ & 0.0546 & 1.4653 & 1.4695 & 1.4687 & \multirow{2}{*}{ Failure } \\
\hline & & $D_{A}$ & 0.0027 & 0.0076 & 0.0362 & 0.0376 & \\
\hline & \multirow{2}{*}{$\left(0^{\circ}, 1700 \Omega\right)$} & $M D_{C}$ & 0.1191 & 0.0052 & 1.4749 & 1.4676 & \multirow{2}{*}{ Failure } \\
\hline & & $D_{A}$ & 0.0025 & 0.0017 & 0.0342 & 0.0548 & \\
\hline & \multirow{2}{*}{$\left(0^{\circ}, 1800 \Omega\right)$} & $M D_{C}$ & 0.0014 & 1.4679 & 1.4679 & 1.4672 & \multirow{2}{*}{ Failure } \\
\hline & & $D_{A}$ & 0.0001 & 0.0010 & 0.0175 & 0.0402 & \\
\hline & \multirow{2}{*}{$\left(0^{\circ}, 1900 \Omega\right)$} & $M D_{C}$ & 0.0114 & 1.4658 & 1.4704 & 1.4675 & \multirow{2}{*}{ Failure } \\
\hline & & $D_{A}$ & 0.0017 & 0.0060 & 0.0241 & 0.0271 & \\
\hline & $\left(0^{\circ}, 2000 \Omega\right)$ & $M D_{C}$ & 0.0569 & 0.0007 & 0.0550 & 1.4669 & Failure \\
\hline
\end{tabular}

WT: Wavelet transform

WPT: Wavelet packet transform

CLS: Chaotic-like state

CS: Critical state

PLS: Periodic-like state

$\mathrm{D}_{\mathrm{C}}$ : Chaotic distance

$M D_{C}$ : Maximum of $\mathbf{D}_{C}$

$D_{A}: \quad$ Average of chaotic distance.

\section{Conflict of Interests}

The authors declare that there is no conflict of interests regarding the publication of this article.

\section{Acknowledgments}

This work is supported by Science and Technology Research (12B470002, 14A470004) and Control Engineering Lab Project (KG2011-15) of Henan Province, China, and Youth Foundation (Q2012-28, Q2012-43A) of Henan Polytechnic University, China.

\section{References}

[1] X. Z. Dong and S. X. Shi, "Identifying single-phase-to-ground fault feeder in neutral noneffectively grounded distribution system using wavelet transform," IEEE Transactions on Power Delivery, vol. 23, no. 4, pp. 1829-1837, 2008.

[2] H. Shu and S. Peng, "A fault line detection algorithm for distribution network of overhead line and underground cable mixed lines using S-transform energy from short window data," Transactions of China Electrotechnical Society, vol. 24, no. 10, pp. 152-159, 2009.

[3] X. W. Wang, J. W. Wu, and R. Y. Li, "A novel method of fault selection based on voting mechanism of Prony relative entropy theory," Electric Power, vol. 46, no. 1, pp. 59-65, 2013.

[4] H. C. Shu, L. Gao, R. M. Duan, P. Cao, and B. Zhang, "A novel hough transform approach of fault line selection in distribution networks using total zero-sequence current," Automation of Electric Power Systems, vol. 37, no. 9, pp. 1-7, 2013.

[5] X. Sun, M. Gao, D. Liu, X. Hou, and R. Yuan, "Analysis and processing of electrical fault signals with modified adaptive prony method," Proceedings of the Chinese Society of Electrical Engineering, vol. 30, no. 28, pp. 80-87, 2010.
[6] P. K. Nayak, A. K. Pradhan, and P. Bajpai, "A fault detection technique for the series-compensated line during power swing," IEEE Transactions on Power Delivery, vol. 28, no. 2, pp. 714-722, 2013.

[7] Z.X. Zhang, X. Liu, and P. Zailin, "Fault line detection in neutral point ineffectively grounding power system based on phaselocked loop," IET Generation, Transmission \& Distribution, vol. 8, no. 2, pp. 273-280, 2014.

[8] S. Lin, Z. He, T. Zang, and Q. Qian, "Novel approach of fault type classification in transmission lines based on rough membership neural networks," Proceedings of the Chinese Society of Electrical Engineering, vol. 30, no. 28, pp. 72-79, 2010.

[9] Z. Shu, Z. Y. He, Q. Wang, and S. Lin, "Fault line selection of resonant grounding system based on the characteristics of charge-voltage in the transient zero sequence and support vector machine," Power System Protection and Control, vol. 41, no. 12, pp. 71-78, 2013.

[10] J. G. Yang, R. C. Zhang, and H. Y. Fang, "Application of duffing oscillator signal detection to arcing faults protection," Automation of Electric Power Systems, vol. 30, no. 24, pp. 69-72, 2006.

[11] Z. Q. Sun, C. Z. Chen, Y. L. Gu, and H. Liu, "Incipient fault diagnosis of large scale wind turbine gearbox based on chaos theory and sampling integral technology," Journal of Vibration and Shock, vol. 32, no. 9, pp. 113-117, 2013.

[12] S. Zhang, X. Zhai, X. Dong, L. Li, and B. Tang, "Application of EMD and Duffing oscillator to fault line detection in uneffectively grounded system," Proceedings of the Chinese Society of Electrical Engineering, vol. 33, no. 10, pp. 161-167, 2013.

[13] H. Vahedi, G. B. Gharehpetian, and M. Karrari, "Application of duffing oscillators for passive islanding detection of inverterbased distributed generation units," IEEE Transactions on Power Delivery, vol. 27, no. 4, pp. 1973-1983, 2012.

[14] H. C. Shu, Fault Line Selection of Distribution Power System, China Machine Press, Beijing, China, 2008.

[15] X. Kang, X. Liu, J. Suonan, C. Ma, C. Wang, and L. Yang, "New method for fault line selection in non-solidly grounded system based on matrix pencil method," Automation of Electric Power Systems, vol. 36, no. 12, pp. 88-93, 2012.

[16] H. Zhang, Z. He, and J. Zhang, "Frequency spectrum characteristic analysis of single-phase grounding fault in resonant grounded systems," Automation of Electric Power Systems, vol. 36, no. 6, pp. 79-84, 2012.

[17] H. C. Shu and M. M. Zhu, "Faulty line selection based on timefrequency characteristics of transient zero-sequence current," Electric Power Automation Equipment, vol. 33, no. 9, pp. 1-6, 2013. 
[18] Z. Kang, D. Li, and X. Liu, "Faulty line selection with non-power frequency transient components of distribution network," Electric Power Automation Equipment, vol. 31, no. 4, pp. 1-6, 2011.

[19] M. F. Guo, S. D. Liu, and G. J. Yang, "A new approach to detect fault line in resonant earthed system based on Hilbert spectrum band-pass filter and transient waveform recognition," Advanced Technology of Electrical Engineering and Energy, vol. 32, no. 3, pp. 67-74, 2013. 


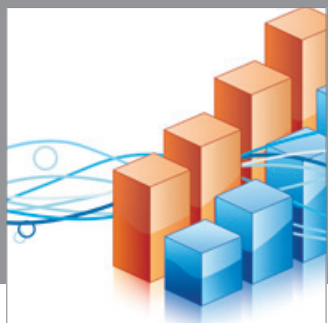

Advances in

Operations Research

mansans

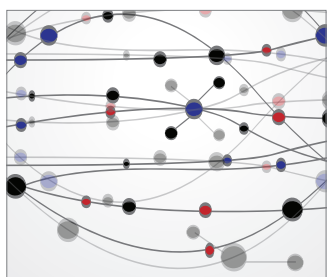

The Scientific World Journal
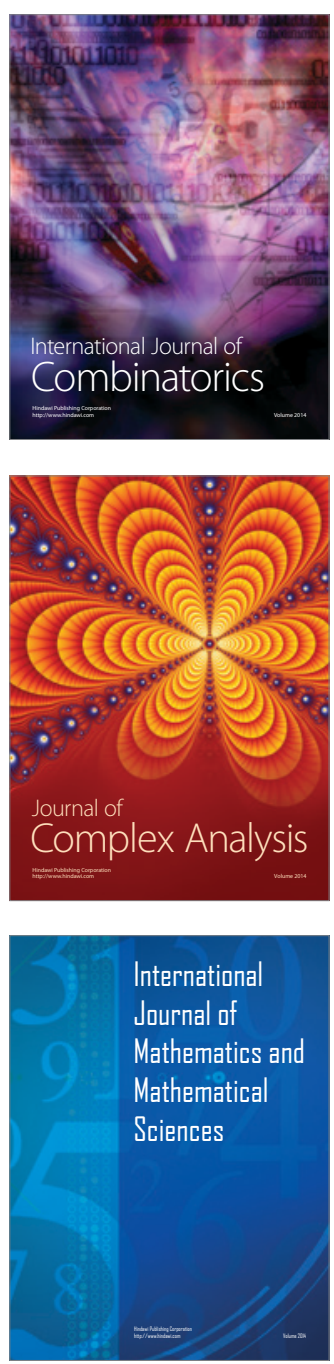
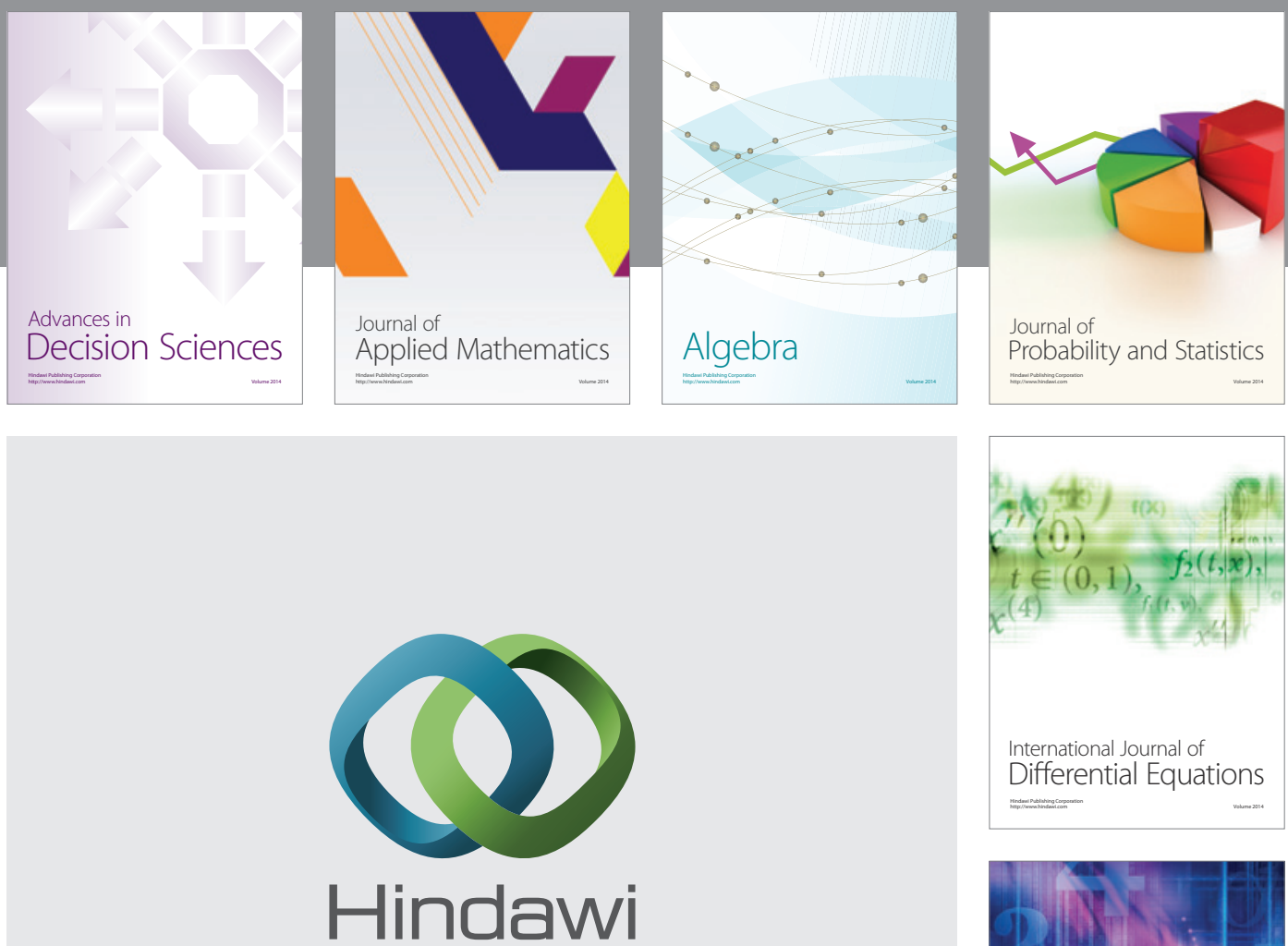

Submit your manuscripts at http://www.hindawi.com
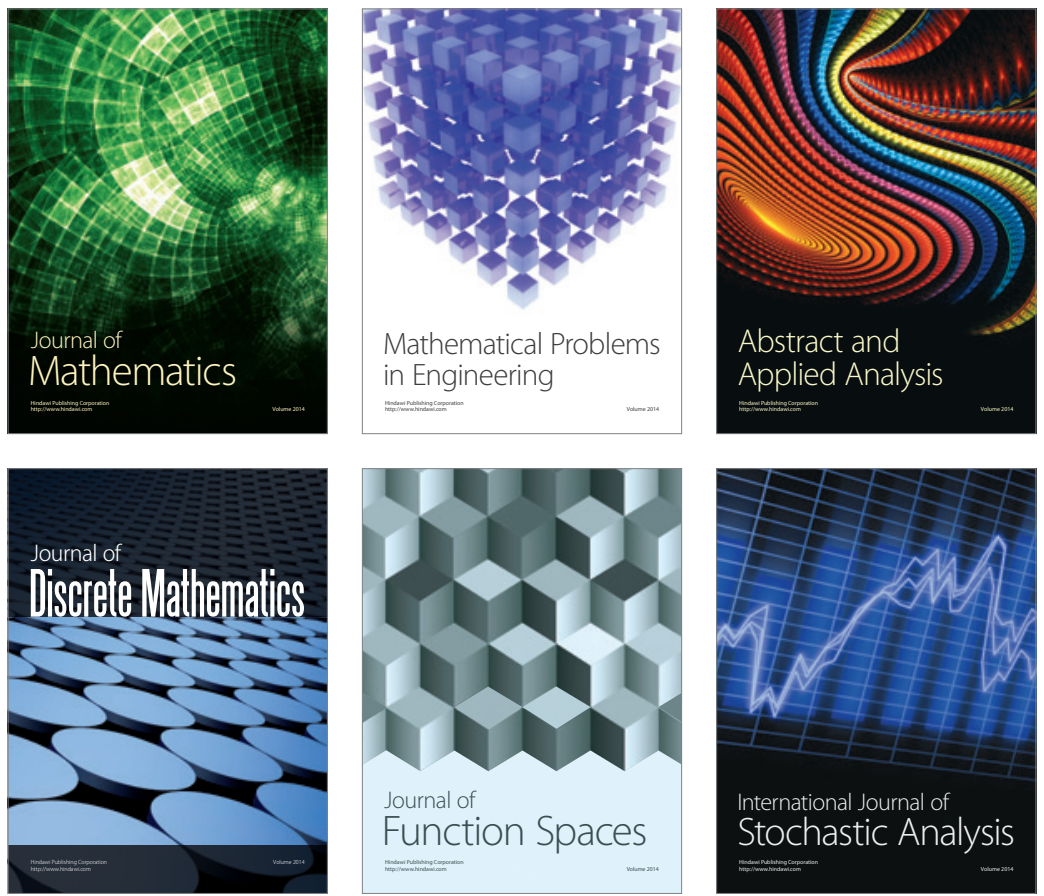

Journal of

Function Spaces

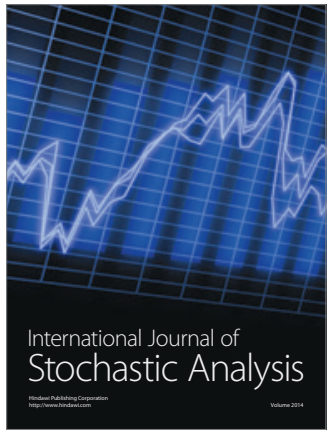

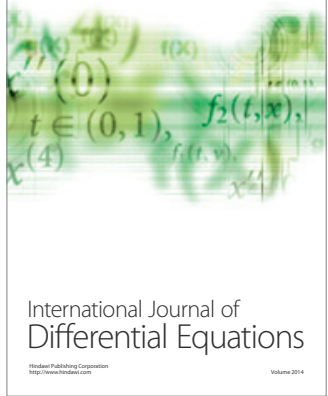
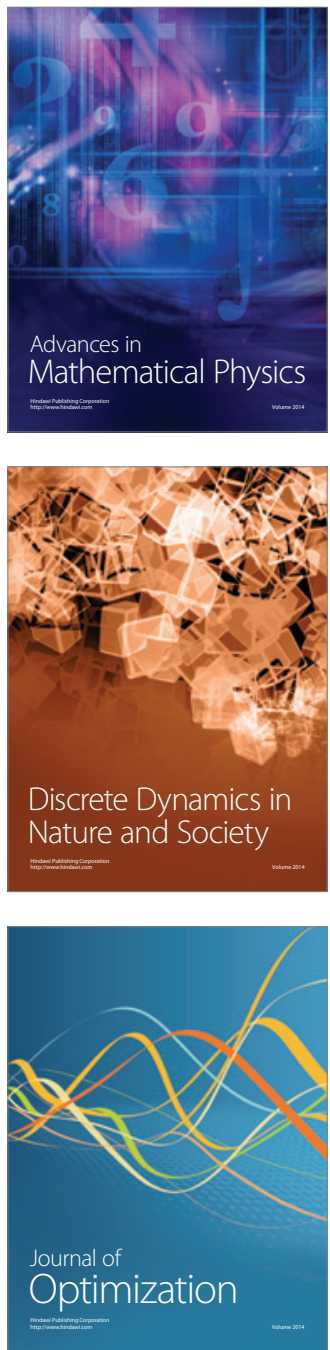